\title{
Task instructions: a part of the social context of participants? A N300 and N400 event-related brain potential study
}

\author{
Sujata Sinha, ${ }^{1,2}$ Sheila Bouten, ${ }^{2}$ Amanda Tardif,,${ }^{1,2}$ Tarlan Daryoush, ${ }^{2}$ Natalie Frye, ${ }^{2}$ Hugo Pantecouteau, ${ }^{2,4}$ \\ Ashely Chau-Morris ${ }^{1,2}$, Maud Haffar, ${ }^{1}$ Ursula Hess, ${ }^{5}$ Milena Kostova ${ }^{6}$ \& J. Bruno Debruille, $, 2,3 *$
}

\author{
Affiliations: \\ ${ }^{1}$ Department of Neurosciences, McGill University, Montréal, Canada. \\ ${ }^{2}$ Research Center of the Douglas Institute, Montréal, Canada. \\ ${ }^{3}$ Department of Psychiatry, McGill University, Montréal, Canada. \\ ${ }^{4}$ École Normale Supérieure, Lyon, France \\ ${ }^{5}$ Department of Psychology, Humboldt University, Berlin, Germany. \\ ${ }^{6}$ Laboratoire de Psychopathologie et Neuropsychologie, EA 2027, Université Paris 8 \\ * Corresponding author: bruno.debruille@mcgill.ca
}

Keywords: social context, stimuli processing, event-related potentials, N300, N400, LPP

Highlights: In a simple image memorization task, stimulus processing depends on whom we are with. Experimenter's task instructions could be part of the social context of participants. N300 and N400 event-related brain potentials depend on social context. N300s and N400s could index inhibitions temporarily setting aside context-inappropriate activations. 
Abstract The early and preconscious processing of stimuli that are meaningful in everyday life includes systematical activations of many semantic, emotional and motor representations. Inhibitions should then occur in order to select, among these primed representations, those that are consistent with the context. Even in a lab this context is social, as it typically consists of the experimenter and of the instructions and stimuli (s)he provides. Three recent N400 studies confirm this social view of experimental settings by showing that socially driven processes affect what was primed by prior stimuli. The small amplitudes of the N400 event-related potentials (ERPs) elicited by stimuli preceded by semantical primes were found to be enhanced by the mere presence of a person next to participants when they know this person did not have the semantic primes. It thus seems that N400 processes inhibit what these primes have activated so that participants can also have the perspective of the uninformed person. This inhibition interpretation implies that N400s should be notably reduced when nothing allows to determine what should be inhibited, that is, when the social context is not defined and when task's instructions require minimal inhibition. We tested this prediction by having a stranger next to participants $(n=29)$ and by presenting meaningful unpredictable images in a simple memorization task. As foreseen, N400s were small. They were enhanced by definable social contexts, that is, in participants alone with the experimenter $(n=30)$ and in those with a friend $(n=$ 36). The amplitudes of the N300s were also enhanced. A second experiment revealed that these N300 and N400 enhancements were larger for friends who felt in the presence of their partner during most of the experiment. As to the late posterior positivities (LPPs) immediately succeeding the N400s, they were found to be larger in the unknown social context of the first experiment, suggesting that more information ended up being placed into the working memory when inhibitions could not occur. These results are compatible with a serial 3-stages framework of the processing of stimuli meaningful in everyday life. Early and broad systematic activations (priming) would be followed by automatic late selections done according to the socialcontext and then, by the participant's consciousness of the meanings of the stimulus in this context. As inadequate late selections would cause impairments of social and cognitive behaviors, the present results could have implications for psychiatric disorders, such as autism and schizophrenia. 


\section{Introduction}

Everyday life stimuli, such as words, faces, objects or scenes, systematically activate meanings, emotions and actions they have been associated to. Even when participants have to decide whether word stimuli are written in red or in black letters, the word "fear" activates its meaning, as well as the related emotion (see for instance affective and non-affective Stroop experiments like Brown, Gore \& Carr, 2002; Frühholz, Jellinghaus \& Herrmann, 2011; Gootjeset al. 2011; Roberts \& Hall, 2008; Strauss, Allen, Jorgensen \& Cramer, 2005; Zhang et al., 2014). Similarly, when participants only have to judge whether or not the picture of a face has already been presented once in the experiment, this face will, nevertheless, instantly be seen as that of a man or that of a woman, young or old, happy or sad, positively or negatively intentioned, even though none of these dimensions is needed to do the task, which can be performed using purely visual features of the picture. Likewise, when participants simply have to look at an object or to count the number of times it appears in an experiment, this object will still systematically activate the actions it has been associated to (see for instance, Tucker \& Ellis, 1998; Borghi \& Riggio, 2009). This occurs even for objects that cannot be manipulated, like faces, which evoke social affordances, such as making eye contacts, starting a conversation or shaking hands (e.g., Debruille, Brodeur \& Porras, 2012). Similarly, buildings are associated to actions, such as walking and entering them, going upstairs and visiting. Even abstract symbols of actions, such as written verbs (e.g., "to jump" or "to dance”), have been shown to lead to such activations (e.g., Grisoni, Dreyer \& Pulvermüller, 2016). These action priming are thought to be a part of the coding of the

meaning of stimuli within the embodied view of cognition (for a review, see for instance Matheson, White \& McMullen, 2015).

Later processes that automatically select which of these systematic activations match the current context may then be necessary to perform the precise task requested by an experimenter. Event-related brain potentials (ERPs) can follow information processing with a high temporal resolution. They could thus help us to test this hypothesis of late automatic selections done according to the experimenter we are with and to what (s)he requires. Two ERPs appear particularly relevant to such automatic selections: the N300s 
and the N400s. The N300s are electrically negative potentials that are maximal at central electrode sites around $300 \mathrm{~ms}$ after the onset of the stimulus. They are evoked by meaningful stimuli other than words, such as, pictures of scenes, faces and objects (see for instance Draschkow et al. 2018; Federmeier \& Kutas, 2002; Schendan \& Ganis 2015; Sitnikova, Kuperberg \& Holcomb, 2003). They are thus elicited by stimuli that, as mentioned, are known to systematically activate the actions they have been associated to, an activation that is now, as indicated above, considered to be part of the coding of their meaning (Matheson, White \& McMullen, 2015). N300s are also evoked by elementary lab stimuli provided that these stimuli have been associated to an action to be performed during the experiment, as revealed by Go/No-Go studies (see for instance Falkenstein et al., 1995; Jodo \& Kayama, 1992). N300s may index a subsequent inhibition of that activation, both for meaningful stimuli other than words, such as picture of objects, and for actionassociated lab-stimuli (Bruin \& Wijers, 2002; Jodo \& Kayama, 1992; Roche, Garavan, Foxe \& O’Mara, 2005; Debruille, Brodeur \& Porras, 2012). This inhibition happens when the actions that were activated (or primed) during the early processing of the stimulus are not appropriate for the task that participants have to perform during the experiment.

The second relevant ERP is the N400, a late negative-going potential whose voltage is maximal around $400 \mathrm{~ms}$ after the onset of the stimulus for words (e.g., Renoult et al., 2012) and around $450 \mathrm{~ms}$ for pictures of faces, objects or scenes (Draschkow et al. 2018; Ganis, Kutas \& Sereno, 1996; Hamm, Johnson \& Kirk, 2002; Nigam Hoffman \& Simons, 1992; Schendan \& Ganis 2015; Sitnikova, Kuperberg \& Holcomb, 2003). It thus peaks right after the N300 ERP. For pictures, it appears as a small bump on the slope going from the N300s to the late posterior positivity (LPP) that follows it (Hamm, Johnson \& Kirk, 2002). The N400s to a stimulus (e.g., to the word "dog" or to the picture of a dog) is larger when preceding stimuli (e.g., the word "coffee" or a picture of a cup of coffee) primed other meanings (e.g., Hamm, Johnson \& Kirk, 2002). Despite the lateness of its onset and of its maximum, the N400s have been proposed to index the access to, or the early activation of, semantic representations corresponding to the unprimed stimulus (e.g., Kieffer, 2002; for a review see Kutas \& Federmeier, 2011). At the opposite, the N400s have 
been suggested to index the late integration of these activated representations within the representation of the context (for recent debates, see for instance Brouwer, Crocker, Venhuizen \& Hoeks, 2017; Mantegna et al., 2019; Ness \& Meltzer-Asscher, 2018). However, the other meanings that were primed by semantically unrelated items might have to be set aside first for the appropriate meaning of the unexpected stimulus to be integrated. The N400s has thus also been proposed to be generated by processes that occur between early activations and late integration and that inhibit these other (inappropriate) meanings (Debruille 1998 \& 2007; Debruille, Pineda \& Renault, 1996; Debruille et al., 2008 and Shang and Debruille, 2013). Importantly, this was also proposed for the meanings inappropriately activated during the early processing of the unprimed stimulus itself.

Interestingly, three studies have looked at semantic processing of individuals when the social context they were in was manipulated (Rueschemeyer, Gardner \& Stoner, 2015; Westley, Kohút \& Rueschemeyer, 2017; Jouravlev et al., 2018). When participants were just with the experimenter, critical words that were primed by prior information elicited relatively small N400s, as usual. Most remarkably, when an additional person who did not have that prior information was sitting next to the participants, these stimuli were found to evoke larger N400s. This effect, which was called the social N400 effect, appears to be consistent with the idea of late inhibition put forward by Debruille (1998 \& 2007); Debruille, Pineda and Renault (1996), Debruille et al., (2008) and Shang and Debruille (2013). It could index the inhibition of what the prior information has just primed so that the participant could also have the perspective of the additional person. Indeed, this N400 enhancement fits the additional amounts of negative electrical activity observed within the N400 time window found when participants manage, as requested, not to think about the information associated to the stimulus (e.g., Bergström, de Fockert \& Richardson-Klavehn, 2009a; 2009b; and Hellersted, Johansson \& Anderson, 2016).

In contrast, social N400s appear to be at odds with the view that the N400 amplitude merely indexes the difficulty to access to, or to activate, representations corresponding to the stimulus (e.g., Brouwer, Crocker Venhuizen \& Hoeks, 2017; Kieffer, 2002; Mantegna, Hintz, Ostarek, Alday \& Huettig, 2019). In 
effect, if this were the case, that is, if social N400s indexed activations, it seems that the N400 amplitude should not depend on the social context in which stimuli are presented but only on the stimuli. On the contrary, as signaled by the authors of the three social-N400 studies (e.g., Berkum, Hagoort \& Brown 1999; West \& Holcomb, 2002; Mantegna, Hintz, Ostarek, Alday \& Huettig, 2019), social N400s could be consistent with the difficulty of integration view of N400 amplitude. According to this integration view, the stimulus could be more difficult to integrate in the representation of the global context when one of the elements of this context, namely, the additional person, did not have the information that eases this integration, which increases complexity for the participant.

Social N400s could thus either index the late automatic selections made (via inhibitions) according to whom we currently are with or a greater integration difficulty. The inhibition hypothesis implies that no such selections could occur when the social context is indefinable, that is, when it includes a person about whom nothing is known, neither who (s)he is, nor what (s)he is confronted to. In effect, in such a situation, it is not possible to determine what should be inhibited. Moreover, it would not be advantageous for the system to set aside activations when some of them might be useful to face whatever an unknown person could happen to do. If the N300s and the N400s actually index the late selections mentioned, they should thus be smaller in the presence of a stranger confronted to unperceived stimuli. If these smaller N300s and N400s are observed even for completely unpredictable meaningful stimuli, that is, for images of scenes, faces and objects that are not primed by prior stimuli, it would bring a strong support to the automatic selection interpretation of social N400s and to the three-stages framework in which these inhibitions processes are included, which is depicted in the Figure 1 below. 


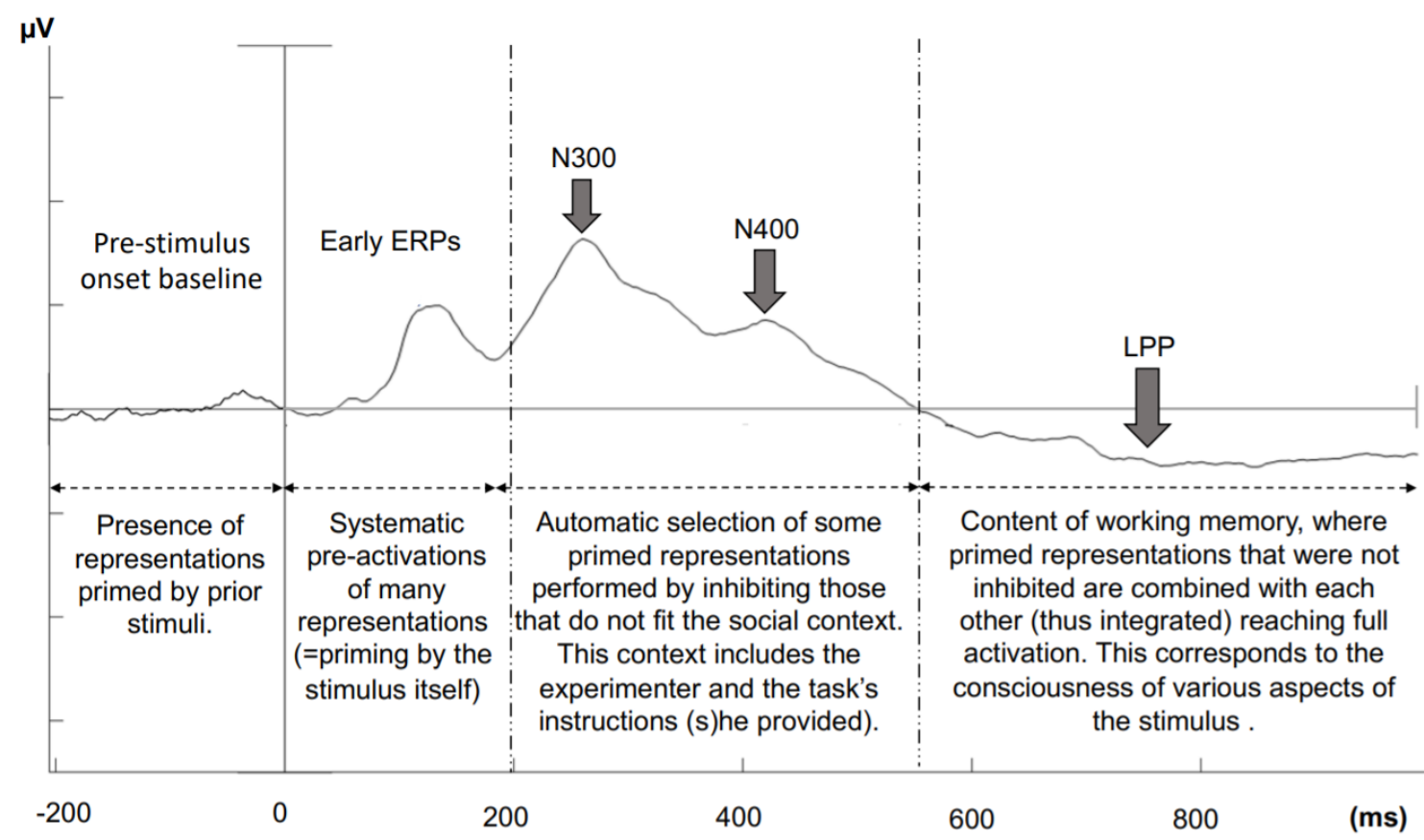

Figure 1. Schema of the theoretical framework including the N400 inhibition hypothesis

Alternatively, according to the integration-difficulty interpretation of social N400s, the amplitudes of N400s should be minimal in the simplest context, that is, when participants are alone. They should be larger when the social context is more complex and thus when social processing is more difficult, that is, when it includes a stranger or a friend in addition to the experimenter. Their presence should trigger an effort at integrating stimulus information within their perspective. 


\section{Experiment 1}

The first experiment of the present study was aimed at testing these two alternate hypotheses. To achieve this goal, we: 1) placed unknown persons next to our participants who were not allowed to talk to them and could thus not have any idea of who they were with, 2) made presentations private so that participants could not see the stimulus their partner was presented with, 3) we used a task that constrains as little as possible the way the stimuli should be processed in order to minimize the requirement of the social context embodied by the experimenter. This was done so that the brain of these participants had no means to determine what late selections should be done to fit that particular context. The experiment also included a "classical" group in which participants were performing the task alone, and thus, in a better-defined social context to the extent that it did not include any really unknown elements. It consisted only of the experimenter who introduced him/herself, welcomed participants, talked with them while placing the electrode cap and provided them with the task instructions and stimuli. According to the inhibition interpretation of the social N400 processes, there should thus be more selections going on in alone participants than in participants with a stranger. A third group of participants was used to further constrain the definition of the social context by introducing an element well-known to the participant, that is, one of his/her close others. This aimed at seeing if both N300s and N400s would be even larger in that social context than in alone participants.

The amplitudes of the ERP that immediately follows the N400s, that is, the late posterior positivity, the LPP, were also used to test whether the automatic-late-selection hypothesis is correct. It predicts that large N400s should be followed by small LPPs, as important inhibitions should be responsible for the consciousness of fewer aspects of the stimulus. In effect, the LPP amplitude is known to be larger when more information is consciously extracted from the stimulus presentation and placed into the working memory. For instance, when stimuli are presented just when there could be an attentional blink, LPPs are larger for stimuli that are consciously perceived than for those that are not (Sergent, Baillet \& Dehaene, 2005; Vogel, Luck \& Shapiro, 1998). LPPs are also larger when more than one meaning is consciously 
perceived, such as when the equivocality (example: irony/sarcasm) of a word is detected (Del Goleto, Kostova \& Blanchet 2016). Similarly, faces that are judged to be ambiguous elicit larger (and later) LPPs than faces that are judged to be either positively or negatively valenced (Debruille, Brodeur \& Hess, 2011). Stimuli that can reactivate many memory episodes evoke larger LPPs relative to those that reactivate only one or a few such episodes (Renoult, Wang, Calcagno, Prévost \& Debruille, 2012). The LPP amplitude was thus used here as an index of the amount of information placed into working memory (Donchin \& Coles, 1988). If the N400 amplitude actually indexes the amount of inhibition that prevent representations activated during the early processing to be integrated in working memory, then larger N400s should be followed by smaller LPPs. Conversely, according to the inhibition hypothesis, smaller N400s of participants with strangers should be followed by larger LPPs.

\section{Methods}

\section{Participants}

All participants had a university degree or were in the process of completing it. They spoke fluent English and had normal or corrected to normal vision. Potential participants were excluded if they consumed more than 12 alcoholic drinks per week, used marijuana more than once per week or if they used any other recreational drug. They were also excluded if they had a history of psychiatric disorders, if they took psychiatric medication or if one of their first-degree relatives had a history of schizophrenia or bipolar disorder.

Thirty-one right-handed participants $(19 \mathrm{~F}, 12 \mathrm{M}$, mean age: 22.25 years, $\mathrm{SD}=3.05)$ were recruited to participate in the classical alone condition. These participants filled out the state-trait anxiety inventory for Adults (STAI) (Spielberger, Gorsuch \& Lushene, 1970) before and after testing to control for the effect of anxiety on ERPs. This was done to exclude the possibility that greater anxiety, such as the one that could be triggered by the presence of a stranger in the critical group, could be responsible for N300 and N400 effects. The critical group included 17 pairs of right-handed participants (24 F, 10 M, mean age: 22.05 years, 
$\mathrm{SD}=2.46)$ who did not know each other and were recruited to undergo the task in the stranger condition. A third group of 36 right-handed participants $(27 \mathrm{~F}, 9 \mathrm{M}$, mean age: 23.1 years, $\mathrm{SD}=3.4)$ were recruited to undergo the task in the close other/friend condition. They were 18 pairs of friends, couples or siblings who knew each other for at least 3 years. Having different participants, that is, a separate group for each of the three social contexts (alone, friend and stranger), rather than having all subjects going through one context after the other, was aimed at preventing a persistence of the cognitive strategy developed in the initial social context. $^{2}$

\section{Consent}

The participants read and signed an informed consent form accepted by the Douglas Institute Research and Ethics Board. This board, which follows the principles of the declaration of Helsinki, also approved the experiment (Douglas REB \#12/12).

Stimuli

Stimuli for friends (i.e., close others) and strangers consisted of 280 images selected from the International Affective Picture System (IAPS) (Lang, Bradley \& Cuthbert, 1997). Several striking images were kept to ensure participants' attention was maintained during the tasks. Two different sets of 140 IAPS stimuli were used, one for each of the two blocks of trials. The order of these two blocks was randomized across subject pairs and across alone participants. For alone participants (controls), there were 400 IAPS images randomly assigned into two blocks, each having 200 images as stimuli.

\footnotetext{
${ }^{2}$ Many report, during the $2^{\text {nd }}$ visit of a city for instance, the tendency to perceive things and act in a way influenced by the initial visit and whom they were with. The initial social context could thus have a longlasting influence.
} 


\section{Procedure}

The close partners filled out separate informed consent forms and demographic questionnaires in the presence of each other. They also had the electrode caps placed while they were already side-by-side so they could talk to each other. They were, however, not allowed to talk during the experiment (for the setup, see also Figure 2B).

In contrast, strangers were kept separated before the experiment and during the placement of the electrode cap. The two participants of each pair were then seated side-by-side in front of a single computer screen and told not to talk to each other during the testing (Figure 2B).

A vertical piece of cardboard separated the screen into two parts, so that even if the paired participants turned their heads, they could not see their partner's half of the screen. This was done in order to discourage eye-movements aimed at checking the partner and the stimulus (s)he was presented with. However, while looking at the screen, paired participants could still feel in the presence of their partner, as (s)he was in the very periphery of their visual field. The alone participants performed the task alone (setup: Figure 2A).

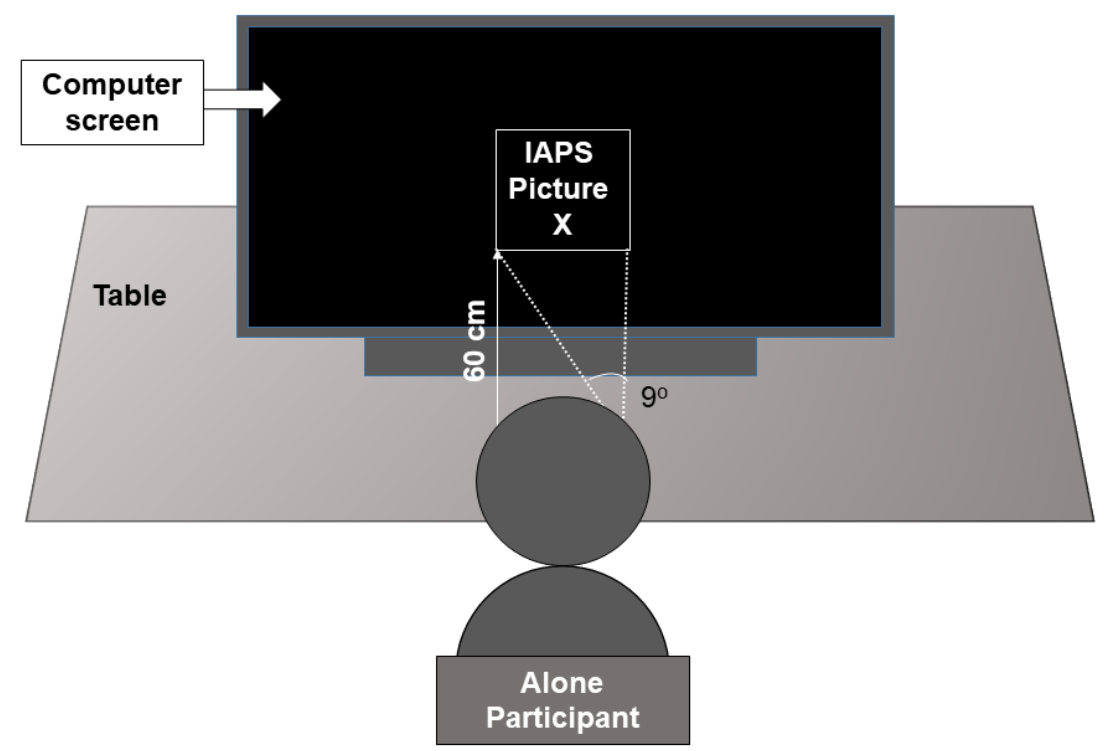

Figure 2A. Lab set up for alone participants 


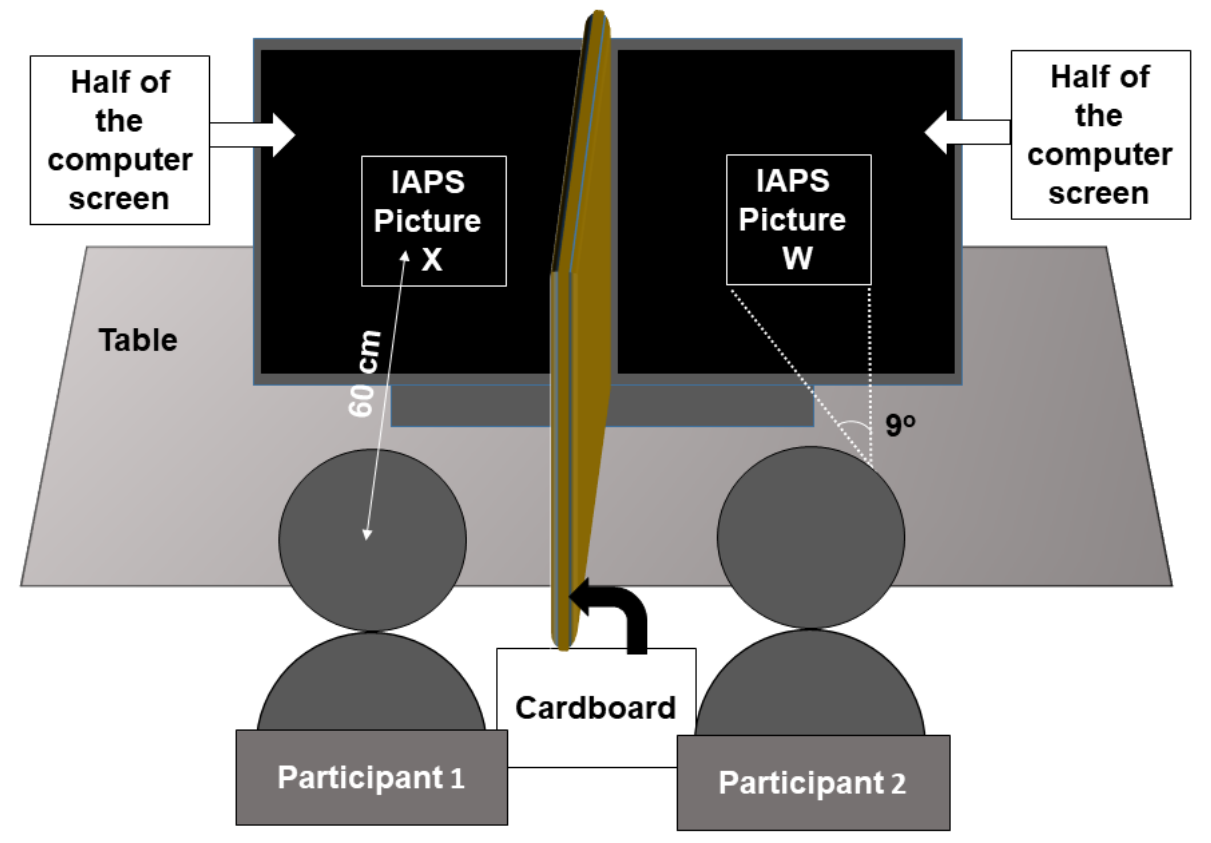

Figure 2B. Lab set up for pairs of friends and strangers. Participants were seated side-by-side. The vertical piece of cardboard that was perpendicular to the computer screen, separates it into two halves. This prevented participants from perceiving the stimulus his/her partner was presented with on the other half.

Participants were separately told to memorize each image. This task was chosen to maintain attention without inducing a focus on a particular aspect of the stimuli, which could have caused an inhibition of the representations corresponding to the other aspects. This no-decision task was also preferred as it avoids any closure of processing that could occur once a decision is made. Participants were not told that there was no memory test afterwards. As in Figure 3, each stimulus was presented for 1000 ms simultaneously to each member of the pair and was followed by a white screen with a black fixation cross, the duration of which randomly varied between 790 and 1500 ms to prevent the development of a contingent negative variation before the next trial. For alone participants, only one image appeared on the screen at a time. Participants were told they could blink during the fixation cross but not during image presentation. 


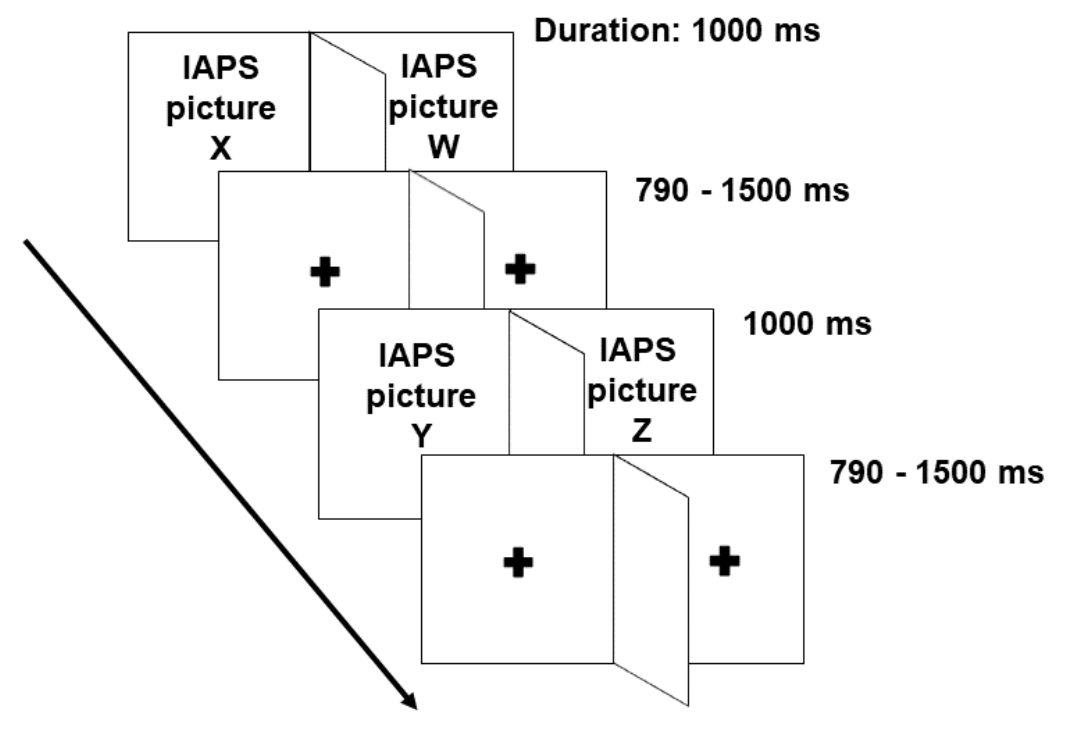

Figure 3. Timing of the presentation of the International Affective Picture System (IAPS) stimuli used for the experiment. For participants in pairs the two images that appeared simultaneously at each trial, one on each half of the screen, were randomly either identical or different. Partners were announced, in a counterbalanced way, before one block of trials that they will see identical images and before the other block, that they will see different ones

\section{Data acquisition}

The electro-encephalogram (EEG) was recorded from 28 electrodes mounted on an elastic cap (ElectroCap International) according to the modified expanded 10-20 system (Committee, 1991). For each participant, these electrodes were grouped into a sagittal (Fz, Fcz, Cz and Pz), a parasagittal (FP1/2, F3/4, $\mathrm{Fc} 3 / 4, \mathrm{C} 3 / 4, \mathrm{Cp} 3 / 4, \mathrm{P} 3 / 4$, and $\mathrm{O} 1 / 2)$ and a lateral (F7/8, Ft7/8, T3/4, Tp7/8 and T5/6) subset of electrodes (SoE). There was a complete separate set of amplifiers for each participant. The right earlobe served as the reference while the ground was taken from an electrode two centimeters in front of Fz. For 
both sets of amplifiers, a $60 \mathrm{~Hz}$ electronic notch filer was used. The high- and low-pass filter, half-amplitude cut-offs were set at 0.01 and $100 \mathrm{~Hz}$, respectively. Out of the two sets of amplifiers (one set for each of the two participants of a pair), there was one set for which 20,000 gain was not reliable. Hence, the EEG signals for the pairs were amplified 10,000 times and 20,000 times for alone participants. EEG signals were then digitized online at a sampling rate of $248 \mathrm{~Hz}$ and recorded in a single file of $56(28 \times 2)$ channels when hyperscanning pairs of participants (friends and strangers) and in a file having only 28 channels for alone participants.

Data processing and measures

EEG offline analysis was performed with MATLAB R2013a using the BBCI (Blankertz et al., 2016) and EEGLAB (Delorme \& Makeig, 2004) toolboxes. The continuous EEG signal was cut into epochs starting $200 \mathrm{~ms}$ before and ending $1200 \mathrm{~ms}$ after the onset of the stimuli. To place these epochs on the baseline, their mean voltages within the -200 to $0 \mathrm{~ms}$ time window were computed and subtracted to each point of the entire epoch. Automatic rejection criteria were set to remove trials where the EEG epoch was contaminated by eye movements, excessive myogram, amplifier saturations or analog to digital clippings. Trials including voltages outside the $+/-100 \mu \mathrm{V}$ at FP1/2 and F8/7 and voltages outside the $+/-75 \mu \mathrm{V}$ range for the other electrodes were excluded as well as trials where clipping exceeded a 100 ms duration. Participants having less than 30 accepted trials were discarded, leaving 30 in the alone group, 36 in the friends and 29 in the stranger group. The mean number of accepted trials for the alone group was 180 $(\mathrm{SD}=66)$, for friends, 212. $(\mathrm{SD}=50)$ and for strangers, $208(\mathrm{SD}=122)$. The ERPs were calculated for each participant in a $1400 \mathrm{~ms}$ time window, beginning $200 \mathrm{~ms}$ before the onset of the stimulus and lasting for $1200 \mathrm{~ms}$ after stimulus onset. Following the averaging, each file (including $28 \times 2=56$ channels) for the pairs was divided into two files, each containing the ERPs of a single participant. The files were visually inspected to detect electrodes with no distinguishable ERPs. Such sites were replaced by the average of its neighboring electrodes (see Appendix 1). The mean voltages of these ERPs were measured in the N300 
(200 to $350 \mathrm{~ms}$ ), N400 (350 to $550 \mathrm{~ms}$ ) and LPP (650-950 ms) time windows for each electrode and each participant. A 80-125 ms time window of measure was added to explore the significance of the unexpected differences found in the time window of the occipital P1 at O1 and O2 and a 110-160 ms time window of measure was added to explore the significance of the unexpected differences found in the time window of the central N1s.

Analyses

For four time-windows (N1, N300, N400 and LPP), three mixed-model repeated-measures ANOVAs, one for each subset of electrodes (SoE), were run to analyze the measures using a multivariate approach. They had the presence of other (alone vs. friends, alone vs. strangers and friends vs. strangers) as the betweensubject factor. They had antero-posterior electrode as a within-subject factor for the sagittal SoE. For the parasagittal and lateral SoE, a second within-subject factor, hemiscalp (right vs. left), was included. Because of pre-zero differences between the groups, FP1/2 were not included in the analyses. The Greenhouse \& Geisser's (1959) procedure was used when required to compensate for the heterogeneity of variances, in which case the original degrees of freedom and the corrected $\mathrm{p}$ values are reported together with the epsilon (E). Independent sample t-tests were conducted on single electrodes for post hocs and for the fifth timewindow, that of the occipital P1, at $\mathrm{O} 1$ and at $\mathrm{O} 2$. 


\section{Results}
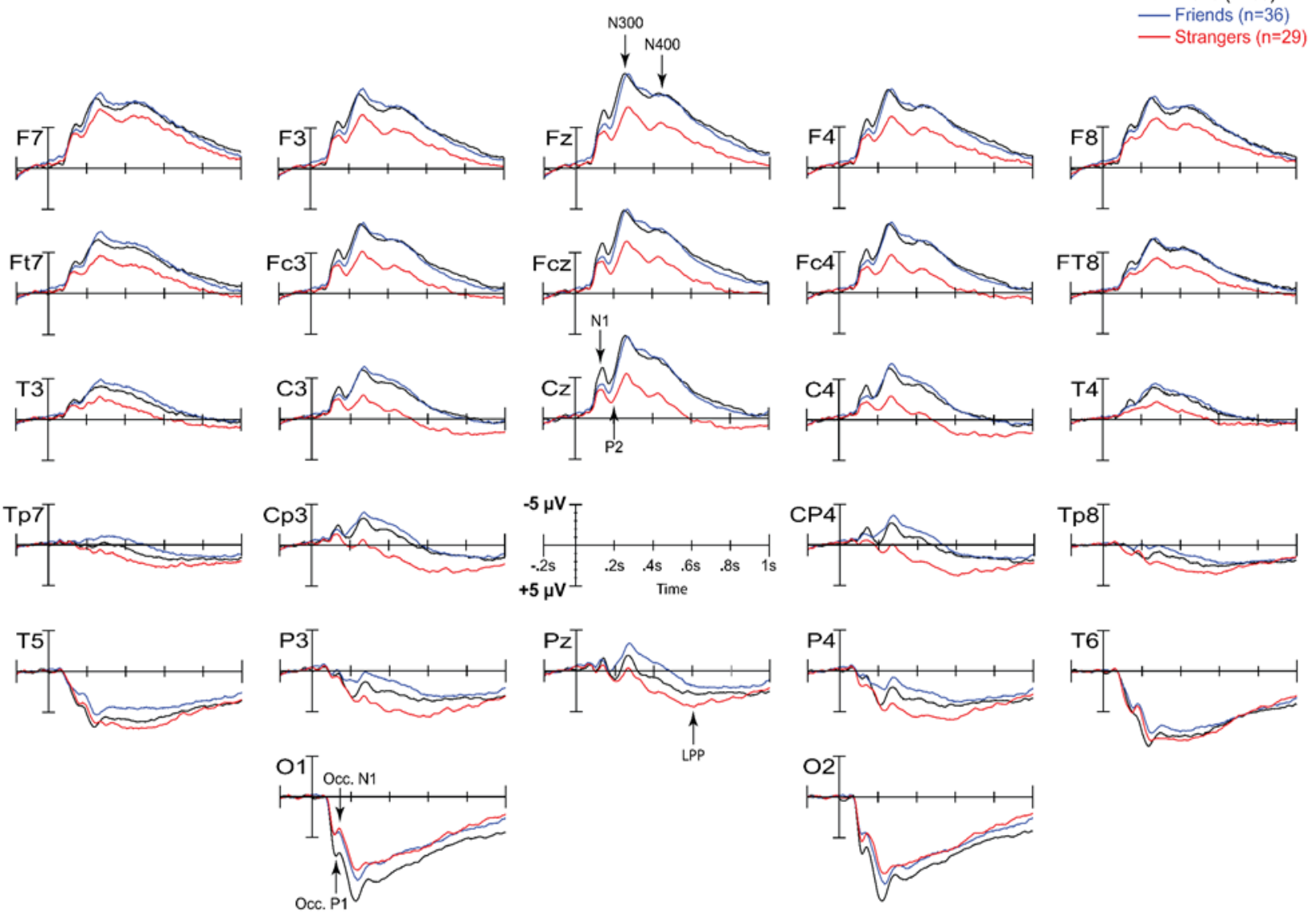

Figure 4. Grand averages ERPs elicited by the IAPS images during the simple memorization task in experiment 1 in the participants who were alone $(n=30)$, with a stranger $(n=29)$ or with a close other or a friend $(\mathrm{n}=36)$

The visual inspection of the grand averages (Figure 4) reveals that ERPs of strangers appear to be less negative than ERPs of friends and of alone participants from the beginning of the N300s to the end of the LPP time window at the sagittal, parasagittal and the lateral subsets of electrodes (SoEs). Figures 5A and 5B, which display subtraction ERPs, better illustrate the time course and scalp distribution of these ERP differences between social contexts. These subtractions include unexpected differences in two early time windows, one around $100 \mathrm{~ms}$ at occipital electrodes and one around $135 \mathrm{~ms}$ at many electrodes. 

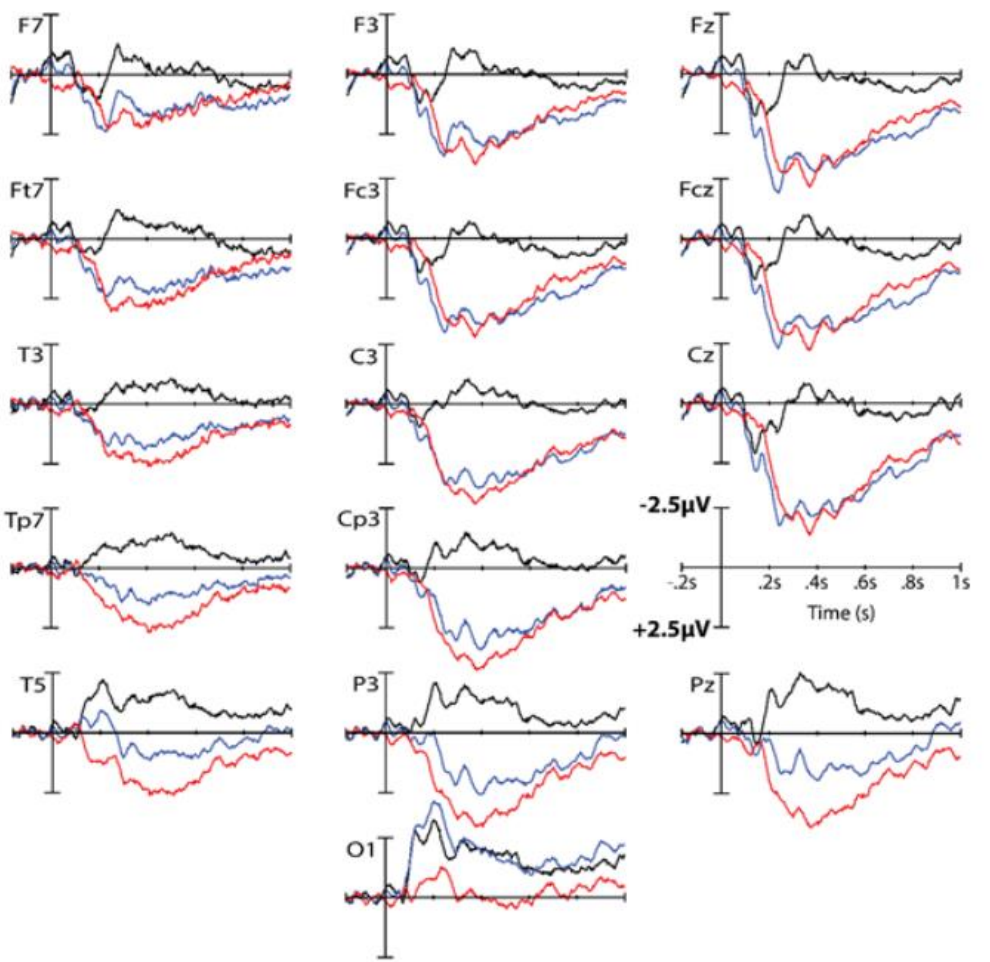
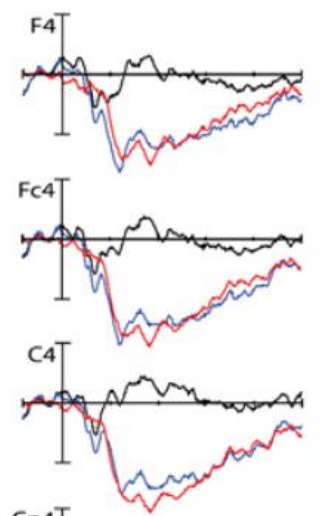

- Friends minus Alone

- Strangers minus Alone

- Strangers minus Friends
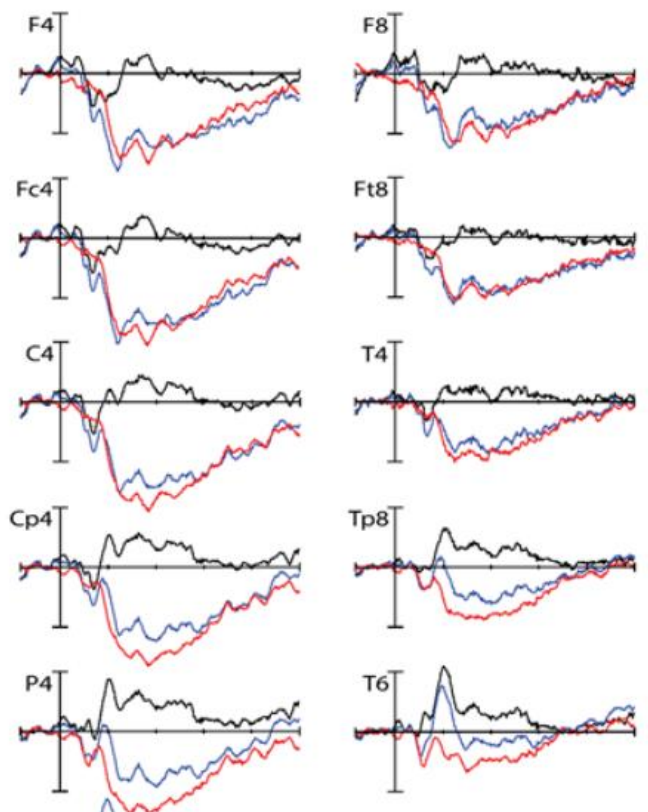

Figure 5A. Subtractions of the ERPs of the alone condition (control) from the ERPs of the friendand from the ERPs of the stranger-condition as well as the subtraction of strangers' ERPs from those of the friends. The larger size of the differences in the time window of the N300s (particularly at $\mathrm{Cz}$ ) suggests that these differences were not due to the modulation of only one long lasting component. 


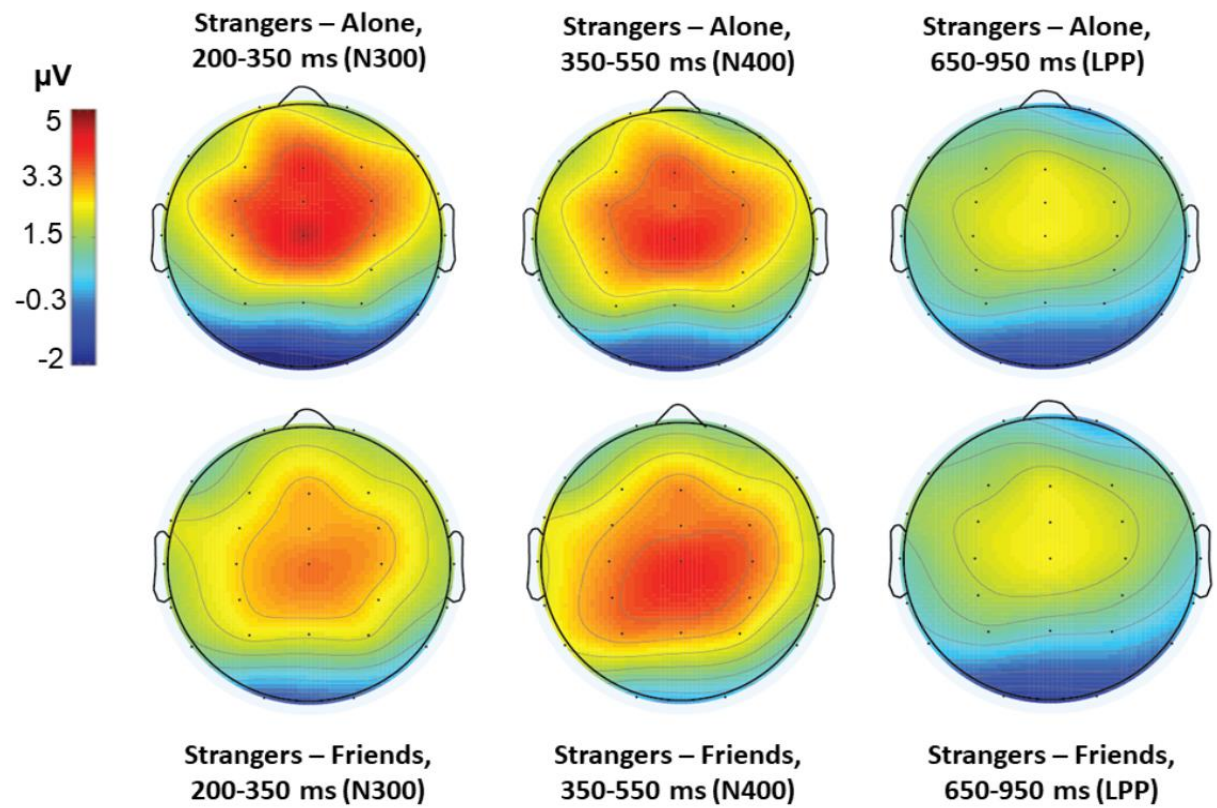

Figure 5B. Spline interpolated iso-voltage maps of the above subtractions

\section{Occipital P1s (80 - 125 ms)}

Table 1 First experiment. Results of independent samples t-tests run with mean voltages in the P1 (80-125 $\mathrm{ms}$ ) time window at $\mathrm{O} 1$ and $\mathrm{O} 2$ electrode sites (ns : not significant)

\begin{tabular}{|c|c|c|c|c|c|c|c|c|}
\hline $\begin{array}{c}\text { Social } \\
\text { Contexts } \\
\text { (groups) }\end{array}$ & Electrode & $\begin{array}{c}\text { Group1 } \\
\text { (Mean, SD) }\end{array}$ & $\begin{array}{c}\text { Group2 } \\
\text { (Mean, SD) }\end{array}$ & $\mathbf{F}$ & $\mathbf{d f}$ & $\mathbf{t}(\mathbf{d f})$ & $\boldsymbol{P}$ & $\begin{array}{c}\text { Effect size } \\
\text { (Cohen's } \\
\text { D) }\end{array}$ \\
\hline \multirow{2}{*}{$\begin{array}{c}\text { Alone vs. } \\
\text { Strangers }\end{array}$} & $\mathrm{O} 1$ & $\begin{array}{c}\text { Alone } \\
(5,4.6)\end{array}$ & $\begin{array}{c}\text { Strangers } \\
(3.37,2.86)\end{array}$ & 1.12 & 57 & 1.63 & 0.054 & 0.42 \\
\cline { 2 - 9 } & $\mathrm{O} 2$ & $\begin{array}{c}\text { Alone } \\
(4.89,3.81)\end{array}$ & $\begin{array}{c}\text { Strangers } \\
(3.89,3.28)\end{array}$ & 0.14 & 57 & 1.08 & $\mathrm{~ns}$ & $\mathrm{Ns}$ \\
\hline \multirow{2}{*}{$\begin{array}{c}\text { Friends vs. } \\
\text { Strangers }\end{array}$} & $\mathrm{O} 1$ & $\begin{array}{c}\text { Friends } \\
(3.58,3.29)\end{array}$ & $\begin{array}{c}\text { Strangers } \\
(3.37,2.86)\end{array}$ & 0.08 & 63 & 0.26 & $\mathrm{~ns}$ & $\mathrm{Ns}$ \\
\cline { 2 - 9 } & $\mathrm{O} 2$ & $\begin{array}{c}\text { Friends } \\
(3.29,3.34)\end{array}$ & $\begin{array}{c}\text { Strangers } \\
(3.89,3.28)\end{array}$ & 0.07 & 63 & -0.72 & $\mathrm{~ns}$ & $\mathrm{Ns}$ \\
\hline \multirow{2}{*}{$\begin{array}{c}\text { Alone vs. } \\
\text { Friends }\end{array}$} & $\mathrm{O} 1$ & $\begin{array}{c}\text { Alone } \\
(5,4.6)\end{array}$ & $\begin{array}{c}\text { Friends (3.58, } \\
3.29)\end{array}$ & 0.74 & 64 & 1.46 & $\mathrm{~ns}$ & $\mathrm{Ns}$ \\
\cline { 2 - 9 } & $\begin{array}{c}\text { Alone } \\
(4.89,3.81)\end{array}$ & $\begin{array}{c}\text { Friends } \\
(3.29,3.34)\end{array}$ & 0.37 & 64 & 1.82 & 0.037 & 0.44 \\
\hline
\end{tabular}


Table 1 reveals that the amplitudes of the occipital P1 was (marginally) significantly larger for alone than for strangers at $\mathrm{O} 1$ and for alone than for friends at $\mathrm{O} 2$.

\section{Comparing participants who were with a stranger to those who were alone}

Table 2 show that the ANOVAs run on the measures made in the 110-160 ms time window revealed that N1 amplitudes were smaller at sagittal and lateral sets of electrodes (SoE) in the participants who were with a stranger than in those who were alone. This social context effect interacted with electrodes at the sagittal and parasagittal SoE. The ANOVAs run on the measures made in the 200-350 ms post-stimulus onset and on those made in the 350-550 ms time window revealed that the amplitude of the N300s and of the N400s were also smaller for those with a stranger. Meanwhile, LPP amplitudes were larger at sagittal, parasagittal and lateral SoE.

Table 2 Experiment 1. Alone vs. Strangers. Results of the ANOVAs run with the mean voltages of ERPs in the N1, N300, N400 and LPP time windows (ns : not significant)

\begin{tabular}{|c|c|c|c|c|c|c|c|c|c|c|}
\hline \multirow{2}{*}{$\begin{array}{c}\text { Mean } \\
\text { voltages } \\
\text { within } \\
\text { time } \\
\text { window }\end{array}$} & \multirow{2}{*}{$\begin{array}{c}\text { Set of } \\
\text { Electrodes } \\
\text { (SoE) }\end{array}$} & \multicolumn{4}{|c|}{$\begin{array}{l}\text { Main effect of social } \\
\text { contexts (groups) }\end{array}$} & \multicolumn{5}{|c|}{$\begin{array}{l}\text { Interactions of social contexts } \\
\text { with electrodes }\end{array}$} \\
\hline & & df & $\mathbf{F}$ & $P$ & $\mathbf{\eta}_{\mathrm{p}}^{2}$ & df & $\mathbf{F}$ & $P$ & $\mathbf{\eta}_{\mathrm{p}}^{2}$ & $\epsilon$ \\
\hline \multirow{3}{*}{$\begin{array}{c}\mathrm{N} 1 \\
(110-160 \\
\mathrm{ms})\end{array}$} & Sagittal & 1,57 & 7.39 & 0.009 & 0.12 & 3,171 & 4.76 & 0.022 & 0.07 & 0.44 \\
\hline & Parasagittal & 1,57 & 2.43 & ns & ns & 5,285 & 7.51 & 0.006 & 0.12 & 0.22 \\
\hline & Lateral & 1,57 & 4.94 & 0.003 & 0.08 & 4,228 & 2.6 & ns & ns & 0.27 \\
\hline \multirow{3}{*}{$\begin{array}{c}\text { N300 } \\
(200-350 \\
\text { ms })\end{array}$} & Sagittal & 1,57 & 11.4 & 0.001 & 0.17 & 3,171 & 11 & $21 \times 10^{-5}$ & 0.16 & 0.52 \\
\hline & Parasagittal & 1,57 & 7.52 & 0.008 & 0.11 & 5,285 & 12.08 & $28 \times 10^{-5}$ & 0.175 & 0.26 \\
\hline & Lateral & 1,57 & 8.68 & 0.005 & 0.13 & 4,228 & 3.5 & ns & ns & 0.28 \\
\hline \multirow{3}{*}{$\begin{array}{c}\text { N400 } \\
(350-550 \\
\text { ms })\end{array}$} & Sagittal & 1,57 & 12.36 & 0.001 & 0.17 & 3,171 & 5.75 & 0.009 & 0.09 & 0.51 \\
\hline & Parasagittal & 1,57 & 11.16 & 0.001 & 0.16 & 5,285 & 9.45 & 0.001 & 0.14 & 0.27 \\
\hline & Lateral & 1,57 & 10.69 & 0.002 & 0.16 & 4,228 & 1.28 & ns & ns & 0.28 \\
\hline \multirow{3}{*}{$\begin{array}{c}\text { LPP } \\
(650-950 \\
\mathrm{ms})\end{array}$} & Sagittal & 1,57 & 10.84 & 0.002 & 0.16 & 3,171 & 4.64 & 0.021 & 0.075 & 0.5 \\
\hline & Parasagittal & 1,57 & 6 & 0.017 & 0.095 & 5,285 & 8.72 & 0.002 & 0.13 & 0.28 \\
\hline & Lateral & 1,57 & 3.88 & 0.054 & 0.06 & 4,228 & 1.69 & ns & ns & 0.3 \\
\hline
\end{tabular}




\section{Comparing participants who were with a friend with those who were with a stranger}

No significant difference was found in the N1 time window. N300s and N400s were again smaller in the stranger group and LPPs larger (Table 3).

Table 3 Experiment 1. Friends vs. Strangers. Results of the ANOVAs run with the mean voltages of ERPs in the N1, N300, N400 and LPP time windows

\section{CLICK TO VIEW THE FULL TABLE}

\section{Comparing alone participants to those who were with a friend}

The ANOVAs run to compare friends and alone-participants revealed larger N1s (110-160 ms) in alone participants at the sagittal SoE, an effect that interacted with electrodes. In the N300 (200-350 ms) and N400 (350-550 ms) time windows, social context interacted with electrodes at the sagittal SoE (see Table 4). To find the source of this interaction, a posthoc test was done at Pz, where an independent sample ttest revealed that N400 amplitudes were marginally larger in the friends $(M=-0.15, S D=3.32)$ than in the alone $(\mathrm{M}=1.44, \mathrm{SD}=3.94)$ participants $(\mathrm{F}=0.68, \mathrm{df}=64, \mathrm{t}(64)=1.78, \mathrm{p}=0.038$, Cohen's $\mathrm{D}$ (effect size $)=0.44)$. 
Table 4. Experiment 1. Alone vs. Friends. Results of the ANOVAs run with the mean voltages of ERPs in the N1, N300, N400 and LPP time windows (ns : not significant)

\begin{tabular}{|c|c|c|c|c|c|c|c|c|c|c|}
\hline \multirow{2}{*}{$\begin{array}{c}\text { Mean } \\
\text { voltages } \\
\text { within } \\
\text { time } \\
\text { window }\end{array}$} & $\begin{array}{c}\text { Set of } \\
\text { Electrodes } \\
\text { (SoE) }\end{array}$ & \multicolumn{4}{|c|}{$\begin{array}{c}\text { Main effect of social } \\
\text { contexts (groups) }\end{array}$} & \multicolumn{3}{|c|}{ Interactions of social contexts with } \\
electrodes
\end{tabular}

\section{Size of the effect of social context across N300, N400 and LPP time windows}

Further ANOVAs adding time window as a factor were run to test whether the smaller negativities observed for strangers than for the two other groups were due to the modulation of one long lasting component overlapping N300s, N400s and LPPs or whether social context affects each of these components in specific ways. Consistently with the latter, social context was found to interact with time window (Table 5).

Table 5 Experiment 1. Results of the ANOVAs run adding the time windows as a within-group factor

\section{CLICK TO VIEW THE FULL TABLE}




\section{Testing the replicability of results}

Other statistical tests were run to see whether the effects of social contexts were replicable. Participants were split into two halves: those who were tested first and those who were tested last. The same ANOVAs were run separately in each of those subgroups. The mean values of their voltages in each time window is presented in Figure 6.

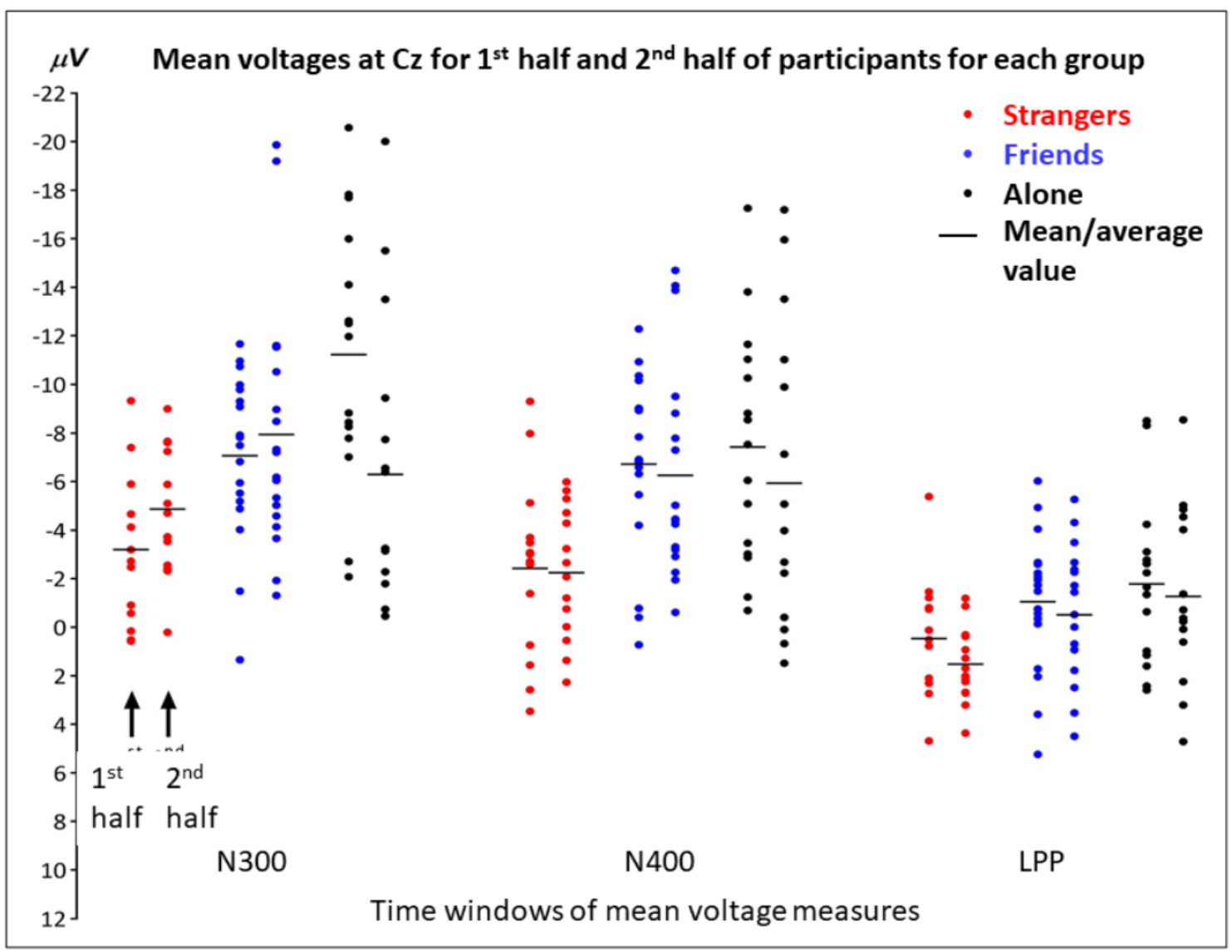

Figure 6. Scatter plots of the mean voltages of the ERPs at $\mathrm{Cz}$ in each time window for each alone(control), friend- and stranger-participant

Tables $6 \& 7$ show that N400s were of significantly smaller amplitudes in strangers than in the two other groups in each half of the participants. N300s were significantly smaller only in the first half. LPPs were significantly larger only for the second half. 
Table 6. Experiment 1. Results of the ANOVAs run on the mean voltages of the ERPs in the late time windows run in the $1^{\text {st }}$ half (15 Alone, 18 Friends and 14 Strangers) of the participants (ns : not significant)

\begin{tabular}{|c|c|c|c|c|c|c|c|c|c|c|}
\hline \multirow{2}{*}{$\begin{array}{c}\text { Mean } \\
\text { voltages } \\
\text { within } \\
\text { time } \\
\text { window }\end{array}$} & \multirow{2}{*}{$\begin{array}{c}\text { Set of } \\
\text { Electrodes } \\
\text { (SoE) }\end{array}$} & \multicolumn{4}{|c|}{$\begin{array}{l}\text { Main effect of social } \\
\text { contexts (groups) }\end{array}$} & \multicolumn{5}{|c|}{$\begin{array}{l}\text { Interactions of social contexts } \\
\text { with electrodes }\end{array}$} \\
\hline & & df & $\mathbf{F}$ & $P$ & $\mathbf{\eta}_{\mathrm{p}}^{2}$ & df & $\mathbf{F}$ & $P$ & $\mathbf{\eta}_{\mathrm{p}}^{2}$ & e \\
\hline \multirow{3}{*}{$\begin{array}{c}\text { N300 } \\
(200-350 \\
\mathrm{ms})\end{array}$} & Sagittal & 2,44 & 12.22 & $6 \times 10^{-5}$ & 0.36 & 6,132 & 6.55 & 0.001 & 0.22 & 0.46 \\
\hline & Parasagittal & 2,44 & 7.56 & 0.002 & 0.26 & 10,220 & 8.94 & $13 \times 10^{-5}$ & 0.28 & 0.26 \\
\hline & Lateral & 2,44 & 7.49 & 0.002 & 0.25 & 8,176 & 6.8 & 0.002 & 0.23 & 0.28 \\
\hline \multirow{3}{*}{$\begin{array}{c}\mathrm{N} 400 \\
(350-550 \\
\mathrm{ms})\end{array}$} & Sagittal & 2,44 & 5.43 & 0.008 & 0.19 & 6,132 & 6.32 & 0.001 & 0.22 & 0.46 \\
\hline & Parasagittal & 2,44 & 3.66 & 0.034 & 0.14 & 10,220 & 5.88 & 0.002 & 0.21 & 0.26 \\
\hline & Lateral & 2,44 & 3.18 & 0.051 & 0.12 & 8,176 & 5.62 & 0.004 & 0.2 & 0.28 \\
\hline \multirow{3}{*}{$\begin{array}{c}\text { LPP } \\
(650-950 \\
\mathrm{ms})\end{array}$} & Sagittal & 2,44 & 1.77 & ns & ns & 6,132 & 3.74 & 0.016 & 0.14 & 0.48 \\
\hline & Parasagittal & 2,44 & 0.38 & ns & ns & 10,220 & 4.2 & 0.012 & 0.16 & 0.26 \\
\hline & Lateral & 2,44 & 0.28 & ns & ns & 8,176 & 2.14 & ns & ns & 0.3 \\
\hline
\end{tabular}

Table 7. Experiment 1. Results of the ANOVAs run on the mean voltages of the ERPs in the late time windows run in the $2^{\text {nd }}$ half (15 Alone, 18 Friends and 15 Strangers) of the participants (ns : not significant)

\begin{tabular}{|c|c|c|c|c|c|}
\hline \multirow{2}{*}{$\begin{array}{c}\text { Mean voltages } \\
\text { within time } \\
\text { window }\end{array}$} & \multirow{2}{*}{$\begin{array}{c}\text { Set of Electrodes } \\
\text { (SoE) }\end{array}$} & \multicolumn{4}{|c|}{ Main effect of social contexts (groups) } \\
\hline & & df & $\mathbf{F}$ & $\boldsymbol{P}$ & $\mathbf{\eta}_{\mathrm{p}}^{2}$ \\
\hline \multirow{3}{*}{$\begin{array}{c}\mathrm{N} 300 \\
(200-350 \mathrm{~ms})\end{array}$} & Sagittal & 2,45 & 1.98 & ns & ns \\
\hline & Parasagittal & 2,45 & 2.6 & ns & ns \\
\hline & Lateral & 2,45 & 2.28 & ns & ns \\
\hline \multirow{3}{*}{$\begin{array}{c}\mathrm{N} 400 \\
(350-550 \mathrm{~ms})\end{array}$} & Sagittal & 2,45 & 3.91 & 0.027 & 0.14 \\
\hline & Parasagittal & 2,45 & 6.07 & 0.005 & 0.21 \\
\hline & Lateral & 2,45 & 5.1 & 0.01 & 0.18 \\
\hline \multirow{3}{*}{$\begin{array}{c}\text { LPP } \\
(650-950 \mathrm{~ms})\end{array}$} & Sagittal & 2,45 & 4.14 & 0.022 & 0.16 \\
\hline & Parasagittal & 2,45 & 4.46 & 0.017 & 0.16 \\
\hline & Lateral & 2,45 & 2.64 & ns & ns \\
\hline
\end{tabular}




\section{Discussion}

Event-related brain potentials (ERPs) elicited by images of the international affective pictures system (IAPS) were thus recorded in pairs of strangers, in pairs of individuals with a close relationship (siblings, couples and friends; all called friends) and in participants who were alone. All these participants were only asked to try to memorize the images. The experiment was done to test whether social N400s index late automatic selections performed to fit the current social context (first hypothesis) or whether these ERPs index integration difficulties (second hypothesis). The automatic selection hypothesis predicted smaller N400s when selections cannot be performed, that is, when the nature of the social context cannot not be precisely defined as when it includes an unknown element, such as a stranger. On the contrary, the integration difficulty hypothesis predicted smaller N400s when the social context can be defined, that is, when participants are alone or with a person they know, and larger N400s when integration is made difficult by unknown contexts.

As predicted by the late automatic-selection interpretation of the social N400 effects, N300s and N400s were much smaller in the context that was less definable, that is, in the presence of an unknown person. These differences were significantly larger in the N300 and in the N400 time window than in the time window of the LPPs (Figure 4, see also the differences waves of the ERP subtractions in Figure 5A), which invalidates the idea that they are only due to one long lasting component that would have overlapped N300s, N400s and LPPs. These differences were found to be replicable as several of them were significant in each of the two halves of the participants (Figure 6, Table 6 and Table 7).

The larger N300s and N400s found in friends and alone than in strangers thus support the idea that late selections can occur when the (experimental and social) context is constraining enough, that is, when it is easier to define precisely. In the social context of a stranger, no knowledge could help determine what should be selected. Moreover, such selections would have reduced the range of possible reactions to this unknown person. Late ERP differences also consisted of smaller LPPs for friends and alone than for

strangers. This suggests that smaller amounts of information were placed into consciousness, as mentioned 
in the introduction. These smaller LPPs of friends are consistent with the inhibition-interpretation of the social N400s proposed here because the late selections it stipulates for friends prevents larger amounts of information to be placed into consciousness.

In contrasts, the present results are at odds with the integration-difficulty interpretation of the social N400s obtained in Rueschemeyer, Gardner \& Stoner (2015), Westley, Kohút \& Rueschemeyer, (2017) and Jouravlev et al. (2018). This interpretation sees the larger N400s obtained in these three studies when the social context was more complex, that is, when it included a uniformed stranger, as a greater effort deployed to integrate meaning. This interpretation thus predicts larger N400s in the presence of a stranger than in easier to define contexts, such as, when alone or with a friend, which was not observed here.

In what follows, we eliminate three explanations of the late differences other than the two hypotheses discussed. The first alternative explanation of the results would have been the influence of a general factor, such as attention. The late timing of the N300, N400 and LPP effects, as well as the wide distribution of the ERP differences across the scalp, (Figures 5A \& 5B) could be consistent with attentional differences. This account appears plausible since being with someone else could have made subjects more distracted and being alone, more concentrated and paying more attention to stimuli. This appears to be true because occipital P1s and N1s were larger for participants who were alone than for those who were with someone else and because this type of differences has been shown to index greater attention to stimuli (e.g., Clark \& Hillyard, 1996; Natale, Marzi, Girelli, Pavone \& Pollmann, 2006). The smaller N300s and N400s of participants with a stranger could thus indicate that they paid less attention to stimuli. However, this attention account can be rejected because the occipital P1s and N1s were also smaller in friends than in alone participants and this did not prevent friends from having large N300s and N400s. Moreover, if the larger N300s and N400s of those with close others and those alone compared to those with strangers had signaled the allocation of greater attentional resources, as these ERPs can (e.g., Cristescu \& Nobre, 2008; McCarthy \& Nobre, 1993), they would have been accompanied by larger LPPs. In effect, the amplitude of LPPs is well-known to positively correlate with the amount of attentional resources allocated to the 
processing of stimuli (e.g., Donchin \& Coles, 1988; Ruchkin, Johnson, Canoune, Ritter \& Hammer, 1990). Attention in itself is thus unable to account for the data.

Emotion did not play a major role in the ERP differences obtained either. Had it been responsible for a notable portion of the ERP effects, it would have been significantly larger in friends than in alone group as Hess, Banse and Kappas (1995) showed that processing stimuli with a close other generates more emotions than processing them with a stranger. This was not the case. The difference between friends' ERPs and alone's ERPs were small compared to the main difference obtained between these ERPs and those of the strangers. Moreover, the ERP modulations do not match those known to be generated by manipulations of emotion (Debruille, Brodeur \& Hess, 2011; Schindler, Bruchmann, Bublatzky \& Straube, 2019).

Lastly, the encoding in episodic memory, which was required by the task, is also unlikely to have played a significant role in the ERP effects found. Deeper encoding is indexed by more positive ERPs for stimuli that are subsequently recognized, particularly during the LPP time window, an effect that is called the Dm ERP effect (Paller, Kutas \& Mayes, 1987; Schott, Richardson-Klavehn, Heinze \& Düzel, 2002). However, for stimuli that are not related to prior stimuli, as was the case here, the Dm effect only impacts ERPs later than the N400 time window (Besson \& Kutas, 1993). In contrast, the effects obtained here started much earlier and the effect was largest in the N300 than in the LPP time window. Moreover, there would be no reason for those with strangers to perform deeper memory encoding than close partners.

The results are thus compatible with the hypothesis of systematic early activations and of late automatic selections indexed by N300s and N400s. Larger N300s-N400s would mean that some of the activations performed during the early processing of the stimulus would then be inhibited in order to keep only what is consistent with the social context. In the people who are alone, the inhibition could allow them to have their own reactions by selecting what is consistent with their own ways. In the participants who were with a stranger, much less inhibitions would occur, which would be indexed by their smaller N300sN400s. More information could then be placed into the working memory, which would be indexed by their 
larger LPPs. These individuals would be better prepared to deal with the unpredictability of a situation including someone about whom nothing is known. 


\section{Experiment 2}

In the first experiment, the late ERP differences between the participants who were alone and those who were with a close other were smaller than the differences between alone and strangers (Figure 4). In the presence of a close other, and thus with a trusted person, the memorization task required during the first experiment and the variety of the IAPS images used as stimuli might have been sufficient to capture the attention of participants. At least some of them might have then forgotten the presence of their partner and no longer felt in this presence during the experiment. The second experiment thus aimed at testing whether the late ERP differences between alone and friends would have been larger in participants who continue to feel in the presence of their friend during most of the experiment by having even larger N300s and N400s and smaller LPPs. To test this prediction, we recruited new pairs of close others and placed each of the two partners of each pair in a particular room, which was separated from the room where the other partner was by a double glass window and a curtain covering that window (Figure 7).

\section{Methods}

\section{Participants}

Eighty-six right-handed participants $(64 \mathrm{~F}, 22 \mathrm{M}$, mean age: 23.1 years, $\mathrm{SD}=3$ ) were recruited using the same criteria as those used to recruit the friend pairs of the first experiment.

The consent was the same as that of experiment 1.

The stimuli used included either those of the first or those of the second block of stimuli used in experiment 1 , in order to prevent fatigue. There was thus a total of 140 trials. 
The procedure was the same as that of experiment 1, except that each of the two partners of each pair was seated in a room that was separated from the room of his/her partner by a double glass window and a curtain covering that window. During the EEG cap placement, the curtain was removed so that they could visually interact with each other by looking at each other via the glass window. They were instructed to communicate as much as possible to boost the feeling of the presence of their partners. In contrast, they were not allowed to talk during the experiment and were completely separated by the black curtain in addition to the glass window to prevent them from seeing or hearing each other (Figure 7).

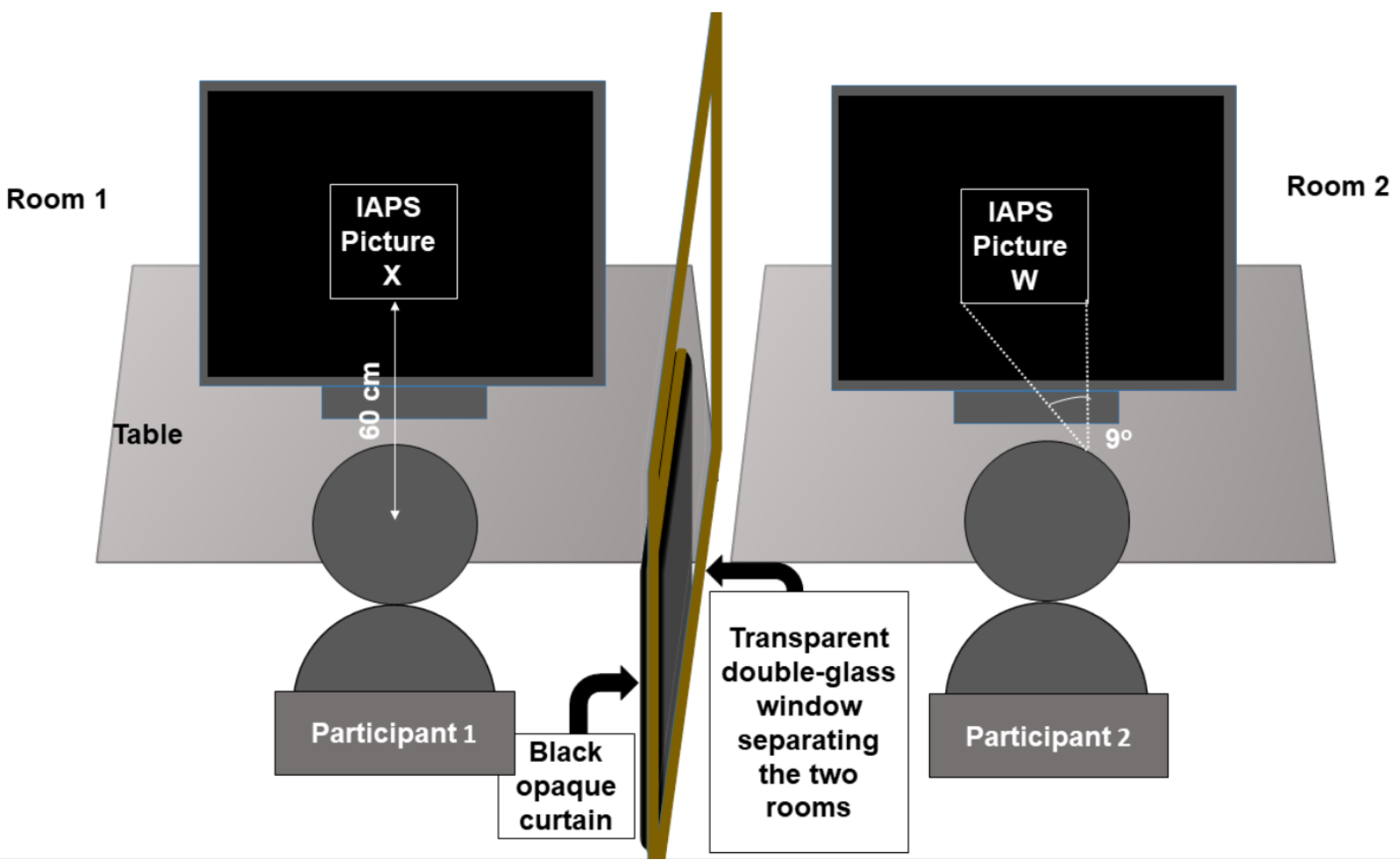

Figure 7. Lab set up for pairs of friends. Each of the two participants of a pair ("partner A" \& "partner B") was sitting in one room in front of his/her computer screen. The two rooms were adjacent and separated from each other by a double glass-window covered by a curtain. 
Task instructions and stimulus presentation (Figure 3) were same as in experiment 1. However, participants were presented with the stimuli on separate computer screens, which could not be seen by the partner because of the black curtain. After the experiment, each partner was separately asked to fill up the debriefing questionnaire in which they were asked to mention the extent to which they continued to feel in the presence of their friends during the experiment (see Appendix 2 for the verbatim of the questions).

Data acquisition, processing and measures were done as in the first experiment. The formulae used to recompute channel without clear ERPs and the channels that had to be ignored are available in Appendix 3. Participants were split into two subgroups according to which item of the debriefing questionnaire (Appendix 2) they checked. Those who selected either the first, the second or the third option and thus who felt in the presence of their friend for at least half of the experiment were placed in the subgroup of those who Felt Together (the FT). Those who chose the fourth or the fifth option were placed into the Felt Alone subgroup (FA). It had 47 participants (33 F, 14 M, mean age: 22.9 years, $\mathrm{SD}=2.8$ ). The FT subgroup consisted of 39 participants (31 F, $8 \mathrm{M}$, mean age: 23.3 years, $\mathrm{SD}=3.3$ ). The average number of accepted trials were $77(\mathrm{SD}=17)$ in the FA- and $72(\mathrm{SD}=15)$ in the FT-subgroup.

Except for the occipital P1s and N1s time windows, where no difference could be seen between subgroups and for which no test was thus performed, analyses were conducted as in the first experiment, using the feeling of being in the presence of the partner (FA vs FT) as the between-subject factor.

For each of these three time-windows, three mixed-model repeated-measures ANOVAs, one for each subset of electrodes (SoE), were run to analyze the measures using a multivariate approach. The tests were conducted similar to those of experiment 1. 


\section{Results}
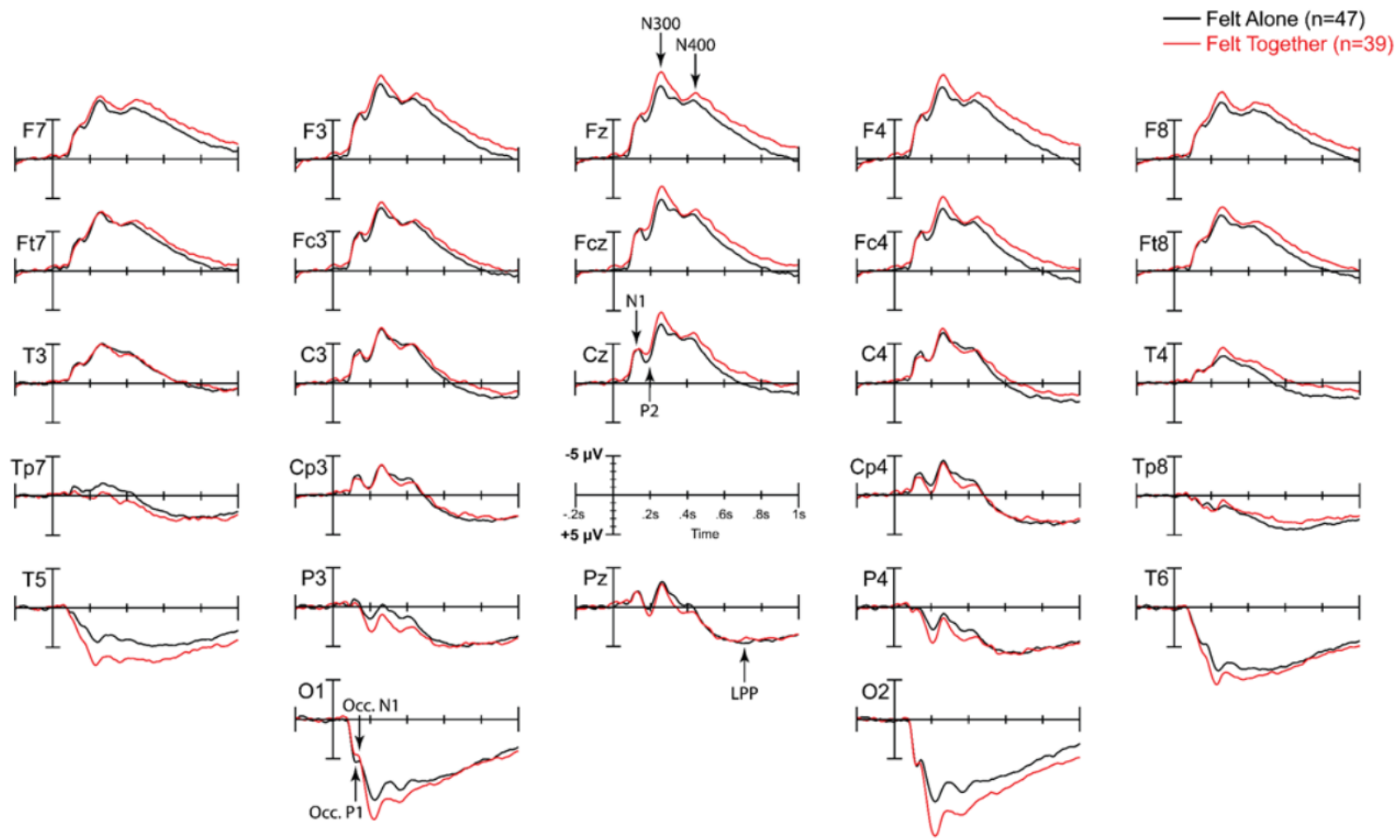

Figure 8. Grand Averages ERPs elicited by the images of the IAPS during a simple memorization task in experiment 2 for each of the two subgroups of participants

The visual inspection of the grand average data (Figure 8) did not reveal any early (i.e., occipital P1 and N1) differences. In contrast, ERPs appeared more negative in those who Felt Together (FTs) than in those who Felt Alone (FAs) from the beginning of the N300 to the end of the LPP time window at anterior electrodes, particularly over the right hemiscalp. In contrast, they were more positive at occipito-temporal and parietal electrodes.

The ANOVAs confirmed the above-mentioned reversal of the direction of the ERPs differences by revealing that subgroup interacted with electrodes at the at all SoEs in the N300 time-window. Similar effects of social contexts were also found in the N400 and LPP time windows, where they interacted with electrodes at the sagittal and parasagittal SoE (Tables 8 to 11). 
Table 8. Experiment 2. Results of the ANOVAs run with the mean voltages of the ERPs in the late timewindows in the participants who Felt Alone and in those who Felt Together (ns : not significant and - : hemiscalp not applicable for sagittal SoE)

\begin{tabular}{|c|c|c|c|c|c|c|c|c|c|c|c|}
\hline \multirow{2}{*}{$\begin{array}{c}\text { Mean } \\
\text { voltages } \\
\text { within } \\
\text { time } \\
\text { window }\end{array}$} & \multirow{2}{*}{$\begin{array}{c}\text { Set of } \\
\text { Electrodes } \\
\text { (SoE) }\end{array}$} & \multicolumn{5}{|c|}{$\begin{array}{l}\text { social context } \mathrm{x} \text { electrode } \\
\text { interactions }\end{array}$} & \multicolumn{5}{|c|}{$\begin{array}{l}\text { social context } \mathrm{x} \text { electrode } \mathrm{x} \\
\text { hemiscalp interactions }\end{array}$} \\
\hline & & df & $\mathbf{F}$ & $P$ & $\eta_{p}^{2}$ & e & Df & $\mathbf{F}$ & $\boldsymbol{P}$ & $\mathbf{\eta}_{\mathrm{p}}^{2}$ & e \\
\hline \multirow{3}{*}{$\begin{array}{c}\mathrm{N} 300 \\
(200-350 \\
\mathrm{ms})\end{array}$} & Sagittal & 3,252 & 4.97 & 0.018 & 0.05 & 0.44 & - & - & - & - & - \\
\hline & Parasagittal & 5,420 & 4.74 & 0.020 & 0.05 & 0.28 & 5,420 & 2.88 & 0.034 & 0.03 & 0.62 \\
\hline & Lateral & 4,336 & 7.4 & 0.003 & 0.08 & 0.36 & 4,336 & 0.66 & ns & ns & 0.45 \\
\hline \multirow{3}{*}{$\begin{array}{c}\mathrm{N} 400 \\
(350-550 \\
\mathrm{ms})\end{array}$} & Sagittal & 3,252 & 2.02 & ns & ns & 0.49 & - & - & - & - & - \\
\hline & Parasagittal & 5,415 & 2.03 & ns & ns & 0.29 & 5,415 & 2.32 & ns & ns & 0.29 \\
\hline & Lateral & 4,336 & 4.06 & 0.033 & 0.04 & 0.35 & 4,336 & 1.36 & ns & ns & 0.35 \\
\hline \multirow{3}{*}{$\begin{array}{c}\text { LPP } \\
(650-950 \\
\mathrm{ms})\end{array}$} & Sagittal & 3,252 & 2.34 & ns & $\mathrm{ns}$ & 0.49 & - & - & - & - & - \\
\hline & Parasagittal & 5,420 & 2.77 & ns & ns & 0.3 & 5,420 & 2.71 & 0.039 & 0.03 & 0.66 \\
\hline & Lateral & 4,336 & 3.49 & 0.05 & 0.04 & 0.34 & 4,336 & 0.82 & ns & ns & 0.52 \\
\hline
\end{tabular}

Table 9. Experiment 2. Significant results of the posthoc independent samples Student t-tests run with the mean voltages of the ERPs in N300 time window for the participants who felt alone (FA) and those who felt together (F'T)

\begin{tabular}{|c|c|c|c|c|c|c|c|c|}
\hline \multirow{2}{*}{$\begin{array}{c}\text { Set of } \\
\text { Electrodes } \\
\text { (SoE) }\end{array}$} & \multirow[b]{2}{*}{ Electrode } & $\begin{array}{c}\text { Felt } \\
\text { Alone (FA) }\end{array}$ & $\begin{array}{c}\text { Felt } \\
\text { Together } \\
\text { (FT) }\end{array}$ & \multirow{2}{*}{$\mathbf{F}$} & \multirow[b]{2}{*}{ df } & \multirow[b]{2}{*}{$t(d f)$} & \multirow{2}{*}{$P$} & \multirow{2}{*}{$\begin{array}{c}\text { Effect } \\
\text { size } \\
\text { (Cohen's } \\
\text { D) }\end{array}$} \\
\hline & & (Mean,SD) & (Mean,SD) & & & & & \\
\hline Sagittal & $\mathrm{Fz}$ & $(-7.99,3.98)$ & $(-9.48,3.64)$ & 0.54 & 84 & 1.79 & 0.035 & 0.38 \\
\hline $\begin{array}{c}\text { Parasagittal- } \\
\text { right } \\
\text { hemiscalp }\end{array}$ & $\mathrm{O} 2$ & $(9.04,6.13)$ & $(12.79,7.95)$ & 1.78 & 84 & -2.48 & $75 \times 10^{-4}$ & -0.53 \\
\hline $\begin{array}{l}\text { Lateral-right } \\
\text { hemiscalp }\end{array}$ & F8 & $(-6.34,3.03)$ & $(-7.44,3.66)$ & 0.5 & 84 & 1.76 & 0.042 & 0.33 \\
\hline \multirow{2}{*}{$\begin{array}{l}\text { Lateral-left } \\
\text { hemiscalp }\end{array}$} & Tp7 & $(-1.19,2.7)$ & $(0.04,3.65)$ & 3.41 & 84 & -1.8 & 0.038 & -0.38 \\
\hline & T5 & $(3.76,4.23)$ & $(6.56,4.73)$ & 1.37 & 84 & -2.89 & $25 \times 10^{-4}$ & -0.62 \\
\hline
\end{tabular}


Table 10. Experiment 2. Significant results of the post-hoc independent samples t-test run on the mean voltages of the ERPs in the N400 time window for the participants who felt alone (FA) and those who felt together (FT)

\begin{tabular}{|c|c|c|c|c|c|c|c|c|}
\hline $\begin{array}{c}\text { Set of } \\
\text { Electrodes } \\
\text { (SoE) }\end{array}$ & \multirow{2}{*}{ Electrode } & $\begin{array}{c}\text { Felt } \\
\text { Alone } \\
\text { (FA) }\end{array}$ & $\begin{array}{c}\text { Felt } \\
\text { Together } \\
\text { (FT) }\end{array}$ & F & df & t(df) & P & $\begin{array}{c}\text { Effect } \\
\text { size } \\
\text { (Cohen's } \\
\text { D) }\end{array}$ \\
\cline { 2 - 8 } & (Mean, SD) & (Mean, SD) & & & & \\
\hline $\begin{array}{c}\text { Lateral-left } \\
\text { hemiscalp }\end{array}$ & T5 & $(4.39,4.27)$ & $(6.34,4.5)$ & 1.19 & 84 & -2.06 & 0.022 & -0.44 \\
\hline
\end{tabular}

Table 11. Experiment2. Significant results of the post-hoc independent samples t-tests run with mean voltages of ERPs within the LPP time window of the participants who felt alone (FA) and of those who felt together (FT)

\begin{tabular}{|c|c|c|c|c|c|c|c|c|}
\hline \multirow[t]{2}{*}{$\begin{array}{c}\text { Set of } \\
\text { Electrodes } \\
\text { (SoE) }\end{array}$} & \multirow[t]{2}{*}{ Electrode } & $\begin{array}{c}\text { Felt } \\
\text { Alone } \\
\text { (FA) } \\
\end{array}$ & $\begin{array}{c}\text { Felt } \\
\text { Together } \\
\text { (FT) }\end{array}$ & \multirow[t]{2}{*}{$\mathbf{F}$} & \multirow[t]{2}{*}{ df } & \multirow[t]{2}{*}{$t(d f)$} & \multirow[t]{2}{*}{$\mathbf{P}$} & \multirow{2}{*}{$\begin{array}{c}\text { Effect } \\
\text { size } \\
\text { (Cohen's } \\
\text { D) }\end{array}$} \\
\hline & & (Mean, SD) & (Mean, SD) & & & & & \\
\hline $\begin{array}{c}\text { Parasagittal } \\
\text { right } \\
\text { hemiscalp }\end{array}$ & $\mathrm{F} 4$ & $(1.52,4.16)$ & $(-3.52,3.34)$ & 2.04 & 84 & 2.42 & $85 \times 10-4$ & 1.32 \\
\hline \multirow{3}{*}{$\begin{array}{l}\text { Lateral- } \\
\text { right } \\
\text { hemiscalp }\end{array}$} & F8 & $(-1.61,2.94)$ & $(-2.74,3.38)$ & 0.22 & 84 & 1.66 & 0.05 & 0.35 \\
\hline & Ft8 & $(-0.39,2.62)$ & $(-1.52,3.16)$ & 0.35 & 84 & 1.82 & 0.036 & 0.39 \\
\hline & $\mathrm{T} 4$ & $(1.66,2.58)$ & $(0.46,2.25)$ & 0.005 & 84 & 2.26 & 0.013 & 0.49 \\
\hline $\begin{array}{l}\text { Lateral- left } \\
\text { hemiscalp }\end{array}$ & T5 & $(4.08,3.19)$ & $(5.28,3.19)$ & 0 & 84 & -1.74 & 0.043 & -0.37 \\
\hline
\end{tabular}




\section{Discussion}

Event-related brain potentials (ERPs) elicited by images of the international affective pictures system (IAPS) were thus recorded once again in pairs of individuals having a close relationship (siblings, couples and friends) called friends. All these participants were again asked to try to memorize the images. They were slip into two subgroups according to whether they felt in the presence of their partner during most of the experiment or whether they felt alone. The experiment was aimed at testing whether, as predicted by the N330 and N400 inhibition hypothesis, the amplitudes of these ERPs would be even greater in those who feel in the presence of their partner. Analyses revealed that this was actually the case at anterior and central scalp sites. At parietal and occipito-temporal ones, it was the contrary. On the other hand, at these latter sites, the amplitudes of the LPP was not modulated whereas, at central and anterior sites, ERPs tended to be less positive for those who felt together than for those who felt alone.

Interpreted within the theoretical framework of the N300 and N400 inhibition hypothesis, these results suggest that a greater amount of "frontal central representations", such as affordances of the IAPS images (Debruille, Brodeur \& Porras, 2012 ; Debruille, Touzel, Segal, Snidal \& Renoult L, 2019) were inhibited or that those that were inhibited were so more deeply in those who felt in the presence of their partner than in those who did not. This would be consistent with a greater impact of that well-defined social context in these participants. Within the same theoretical framework, the larger positivities observed at parietal and occipito-temporal sites for those who felt together suggest that a smaller amount of "parietooccipital representations", such as visual features, nature of the objects present in the IAPS images, as well as their position and values relative to egocentric coordinates, were inhibited, or that they were inhibited to a lesser extent. Accordingly, participants who felt in the presence of their partners would have tended to be, on average, a bit less prone to act upon the content of the image and a bit more conscious of the stimuli.

For the results of this second experiment we can also eliminate the three alternative explanations of the late differences in N300 and N400 ERPs as was done in the discussion of the first experiment. The first alternative explanation of the results was that based on attention. It cannot explain the larger anterior N300s 
of those who felt together because they had occipital P1s and N1s that were of similar amplitude (Figure 8) as those of the participants who felt alone and because they did not have larger LPPs at Pz (see for instance Cristescu \& Nobre, 2008; McCarthy \& Nobre, 1993). Moreover, it appears counter intuitive that those who felt in the presence of their friend would have paid more attention to stimuli than those who felt alone. The other two alternative possibilities, that is, emotion and encoding in episodic memory can be ruled out in the same ways as the ones explained in the discussion of experiment 1.

The results of the experiment 2 are thus compatible with our prediction that felt alone subgroup would have smaller N300s and N400s than the felt together subgroup and further support the inhibition interpretation of the N400 ERP.

\section{General conclusion}

The results of the first experiment supported the interpretation that the social N400s indexes processes that perform a selection among what has been activated by prior stimuli and by the early processing of the current stimulus itself. This selection would allow keeping only the activations that are relevant and appropriate to the social context the participant is currently in. This current social context includes the experimenter and the task instructions (s)he provides, as well as the stimulus presentation (s)he triggers. This would explain why other elements of the social context, such as the presence of a friend, or of a stranger, impact the same late ERPs as the ones that are modulated by the task instructions (e.g., for the N400, see for instance Chwilla, Brown \& Hagoort 1995).

On the other hand, the results of the second experiment revealed that there could be modest differences in the ERPs even within the friends group depending upon the degree of togetherness being felt by the participants during the task. The ERP differences in the "Felt Alone" and "Felt Together" subgroups indicate that more inhibition processes occur in the later, in accordance with a greater impact of precise social contexts on cognitive processes when these well-known contexts are more vivid. 
Further studies should be run with usual cognitive tasks, such as those where participants have to make a decision focused on one (semantic) aspect of the stimulus and to provide a motor response as fast and as accurately as possible. These tasks should decrease or suppress the effects of the mere presence of a stranger by requiring a drastic selection of the aspects of the stimulus that are needed to perform the decision, and thus be responsible for large N300s and N400s and small LPPs, even in the presence of this stranger, as suggested by the preliminary results of an on-going study.

Other studies should also be run with simple tasks, such as the simple memorization used here, in order to see whether the scalp distribution of the larger N300s and N400s depends on the friend that is next to the participant. Inhibitions might depend on him or her as being conscious of some aspects of the stimuli could be inappropriate when in the presence of some persons. On the other hand, within subject studies should be run to evaluate the duration of the cognitive strategy induced by a particular social context. The same participant should be placed first with a stranger and then with a friend. With only a few minutes between the two social contexts, our pilot results suggested that the late ERP differences between strangers and friends are smaller than those of the present study.

The present results open new avenues of research in psychology by demonstrating that the social context can have an impact on information processing, at least in simple memorization tasks. Importantly, such simple tasks are "closer" to most daily-life activities than the repetitive focus on a single aspect of stimuli that many experimental tasks require. The implications of these social context studies could be broad. Not only do they inform the area of cognition and social psychology by showing that the way a stimulus is processed depends on whom we are with, but they might also have important implications for clinical cases. As impairments of social and cognitive behaviors may result from inadequate late selections, the present results could have implications for psychiatric disorders, such as autism and schizophrenia. 


\section{References}

Bergström, Z. M., de Fockert, J. W., \& Richardson-Klavehn, A. (2009a). ERP and behavioural evidence for direct suppression of unwanted memories. NeuroImage, 48(4), 726-737.

Bergström, Z. M., de Fockert, J., \& Richardson-Klavehn, A. (2009b). Event-related potential evidence that automatic recollection can be voluntarily avoided. Journal of Cognitive Neuroscience, 21(7), 1280-1301.

Berkum, J. J. V., Hagoort, P., \& Brown, C. M. (1999). Semantic integration in sentences and discourse: Evidence from the N400. Joumal of Cognitive Neuroscience, 11(6), 657-671.

Besson, M., \& Kutas, M. (1993). The many facets of repetition: A cued-recall and event-related potential analysis of repeating words in same versus different sentence contexts. Journal of Experimental Psychology: Learning, Memory, and Cognition, 19(5), 1115.

Blair, R. J., \& Cipolotti, L. (2000). Impaired social response reversal: A case ofacquired sociopathy'. Brain, 123(6), 1122-1141.

Blankertz, B., Acqualagna, L., Dähne, S., Haufe, S., Schultze-Kraft, M., Sturm, I., .. Müller, K.-R. (2016). The Berlin brain-computer interface: progress beyond communication and control. Frontiers in Neuroscience, $10,530$.

Borghi AM, Riggio L. (2009). Sentence comprehension and simulation of object temporary, canonical and stable affordances. Brain Research, 12530:117-28.

Borod, J. C., Cicero, B. A., Obler, L. K., Welkowitz, J., Erhan, H. M., Santschi, C., .. Whalen, J. R. (1998). Right hemisphere emotional perception: evidence across multiple channels. Neuropsychology, 12(3), 446.

Brouwer, H., Crocker, M. W., Venhuizen, N. J., \& Hoeks, J. C. (2017). A neurocomputational model of the N400 and the P600 in language processing. Cognitive Science, 41, 1318-1352.

Brown, T. L., Gore, C. L., \& Carr, T. H. (2002). Visual attention and word recognition in Stroop color 
naming: Is word recognition" automatic?". Journal of Experimental Psychology: General, 131(2), 220.

Bruin, K. J., \& Wijers, A. A. (2002). Inhibition, response mode, and stimulus probability: a comparative event-related potential study. Clinical Neurophysiology, 113(7), 1172-1182.

Chwilla, D. J., Brown, C. M., \& Hagoort, P. (1995). The N400 as a function of the level of processing. Psychophysiology, 32(3), 274-285.

Clark, V. P., \& Hillyard, S. A. (1996). Spatial selective attention affects early extrastriate but not striate components of the visual evoked potential. Journal of Cognitive Neuroscience, 8(5), 387-402.

Committee, E. N. (1991). Modified expanded 10-20 system. American EEG society. Journal of Clinical Neurophysiology, 35, 200-202.

Cristescu, T. C., \& Nobre, A. C. (2008). Differential modulation of word recognition by semantic and spatial orienting of attention. Journal of Cognitive Neuroscience, 20(5), 787-801.

Debruille (1998). Knowledge inhibition and N400: a study with words that look like common words. Brain and Language, 62(2), 202-220.

Debruille, J. B. (2007). The N400 potential could index a semantic inhibition. Brain Research Reviews, 56(2), 472-477.

Debruille, J. Bruno, Ramirez, D., Wolf, Y., Schaefer, A., Nguyen, T.-V., Bacon, B. A., ... Brodeur, M. (2008). Knowledge inhibition and N400: a within-and a between-subjects study with distractor words. Brain Research, 1187, 167-183.

Debruille, J. B., Pineda, J., \& Renault, B. (1996). N400-like potentials elicited by faces and knowledge inhibition. Cognitive Brain Research, 4(2), 133-144.

Debruille, J. B., Brodeur, M. B., \& Hess, U. (2011). Assessing the way people look to judge their intentions. Emotion, 11(3), 533.

Debruille, J. B., Brodeur, M. B., \& Porras, C. F. (2012). N300 and social affordances: a study with a real person and a dummy as stimuli. PLoS One, 7(10), e47922. 
Debruille, J. B., Touzel, M., Segal, J., Snidal, C., \& Renoult, L. (2019). A central component of the N1 event-related brain potential could index the early and automatic inhibition of the actions systematically activated by objects. Frontiers in Behavioral Neuroscience, 13.u

Del Goleto, S., Kostova, M., \& Blanchet, A. (2016). Impaired context processing during irony comprehension in schizotypy: An ERPs study. International Journal of Psychophysiology, 105, 1725.

Delorme, A., \& Makeig, S. (2004). EEGLAB: an open source toolbox for analysis of single-trial EEG dynamics including independent component analysis. Journal of Neuroscience Methods, 134(1), 921.

Donchin, E., \& Coles, M. G. (1988). Is the P300 component a manifestation of context updating? Behavioral and Brain Sciences, 11(3), 357-374.

Draschkow, D., Heikel, E., Võ, M. L. H., Fiebach, C. J., \& Sassenhagen, J. (2018). No evidence from MVPA for different processes underlying the N300 and N400 incongruity effects in object-scene processing. Neuropsychologia, 120, 9-17.

Falkenstein, M., Koshlykova, N. A., Kiroj, V. N., Hoormann, J., \& Hohnsbein, J. (1995). Late ERP components in visual and auditory Go/Nogo tasks. Electroencephalography and Clinical Neurophysiology/Evoked Potentials Section, 96(1), 36-43.

Fournier, N. M., Calverley, K. L., Wagner, J. P., Poock, J. L., \& Crossley, M. (2008). Impaired social cognition 30 years after hemispherectomy for intractable epilepsy: the importance of the right hemisphere in complex social functioning. Epilepsy \& Behavior, 12(3), 460-471.

Federmeier, K. D., \& Kutas, M. (2002). Picture the difference: Electrophysiological investigations of picture processing in the two cerebral hemispheres. Neuropsychologia, 40(7), 730-747.

Frühholz, S., Jellinghaus, A., \& Herrmann, M. (2011). Time course of implicit processing and explicit processing of emotional faces and emotional words. Biological psychology, 87(2), 265-274. 
Ganis, G., Kutas, M., \& Sereno, M. I. (1996). The search for “common sense”: An electrophysiological study of the comprehension of words and pictures in reading. Journal of Cognitive Neuroscience, 8(2), 89-106.

Greenhouse, S. W., \& Geisser, S. (1959). On methods in the analysis of profile data. Psychometrika, 24(2), 95-112.

Gootjes, L., Coppens, L. C., Zwaan, R. A., Franken, I. H., \& Van Strien, J. W. (2011). Effects of recent word exposure on emotion-word Stroop interference: An ERP study. International Journal of Psychophysiology, 79(3), 356-363.

Grisoni, L., Dreyer, F. R., \& Pulvermüller, F. (2016). Somatotopic semantic priming and prediction in the motor system. Cerebral Cortex, 26(5), 2353-2366.

Hamm, J. P., Johnson, B. W., \& Kirk, I. J. (2002). Comparison of the N300 and N400 ERPs to picture stimuli in congruent and incongruent contexts. Clinical Neurophysiology, 113(8), 1339-1350.

Hellerstedt, R., Johansson, M., \& Anderson, M. C. (2016). Tracking the intrusion of unwanted memories into awareness with event-related potentials. Neuropsychologia, 89, 510-523.

Hess, U., Banse, R., \& Kappas, A. (1995). The intensity of facial expression is determined by underlying affective state and social situation. Journal of Personality and Social Psychology, 69(2), 280.

Jodo, E., \& Kayama, Y. (1992). Relation of a negative ERP component to response inhibition in a Go/Nogo task. Electroencephalography and Clinical Neurophysiology, 82(6), 477-482.

Jouravlev, O., Schwartz, R., Ayyash, D., Mineroff, Z., Gibson, E., \& Fedorenko, E. (2018). Tracking Colisteners' Knowledge States During Language Comprehension. Psychological Science, 0956797618807674.

Kiefer, M. (2002). The N400 is modulated by unconsciously perceived masked words: Further evidence for an automatic spreading activation account of N400 priming effects. Cognitive Brain Research, 13(1), 27-39. 
Kutas, M., \& Federmeier, K. D. (2011). Thirty years and counting: finding meaning in the N400 component of the event-related brain potential (ERP). Annual Review of Psychology, 62, 621-647.

Lang, P. J., Bradley, M. M., \& Cuthbert, B. N. (1997). International affective picture system (IAPS): Technical manual and affective ratings. NIMH Center for the Study of Emotion and Attention, 39_ 58.

Mantegna, F., Hintz, F., Ostarek, M., Alday, P. M., \& Huettig, F. (2019). Distinguishing integration and prediction accounts of ERP N400 modulations in language processing through experimental design. Neuropsychologia, 107199.

Matheson, H., White, N., \& McMullen, P. (2015). Accessing embodied object representations from vision: A review. Psychological Bulletin, 141(3), 511.

McCarthy, G., \& Nobre, A. C. (1993). Modulation of semantic processing by spatial selective attention. Electroencephalography and Clinical Neurophysiology/Evoked Potentials Section, 88(3), 210-219.

Miller, B. L., Chang, L., Mena, I., Boone, K., \& Lesser, I. M. (1993). Progressive right frontotemporal degeneration: clinical, neuropsychological and SPECT characteristics. Dementia and Geriatric Cognitive Disorders, 4(3-4), 204-213.

Natale, E., Marzi, C. A., Girelli, M., Pavone, E. F., \& Pollmann, S. (2006). ERP and fMRI correlates of endogenous and exogenous focusing of visual-spatial attention. European Journal of Neuroscience, 23(9), 2511-2521.

Ness, T., \& Meltzer-Asscher, A. (2018). Lexical inhibition due to failed prediction: Behavioral evidence and ERP correlates. Journal of Experimental Psychology: Learning, Memory, and Cognition, 44(8), 1269.

Nigam, A., Hoffman, J. E., \& Simons, R. F. (1992). N400 to semantically anomalous pictures and words. Journal of Cognitive Neuroscience, 4(1), 15-22.

Paller, K. A., Kutas, M., \& Mayes, A. R. (1987). Neural correlates of encoding in an incidental learning paradigm. Electroencephalography and Clinical Neurophysiology, 67(4), 360-371. 
Renoult, L., Wang, X., Calcagno, V., Prévost, M., \& Debruille, J. B. (2012). From N400 to N300: variations in the timing of semantic processing with repetition. NeuroImage, 61(1), 206-215.

Roche, R. A., Garavan, H., Foxe, J. J., \& O’Mara, S. M. (2005). Individual differences discriminate eventrelated potentials but not performance during response inhibition. Experimental Brain Research, 160(1), 60-70.

Ruchkin, D. S., Johnson, R., Canoune, H. L., Ritter, W., \& Hammer, M. (1990). Multiple sources of P3b associated with different types of information. Psychophysiology, 27(2), 157-176.

Rueschemeyer, S.-A., Gardner, T., \& Stoner, C. (2015). The Social N400 effect: how the presence of other listeners affects language comprehension. Psychonomic Bulletin \& Review, 22(1), 128-134.

Schendan, H. E., \& Ganis, G. (2015). Top-down modulation of visual processing and knowledge after 250 ms supports object constancy of category decisions. Frontiers in Psychology, 6, 1289.

Schindler, S., Bruchmann, M., Bublatzky, F., \& Straube, T. (2019). Modulation of face-and emotionselective ERPs by the three most common types of face image manipulations. Social Cognitive and Affective Neuroscience, 14(5), 493-503.

Schott, B., Richardson-Klavehn, A., Heinze, H. J., \& Düzel, E. (2002). Perceptual priming versus explicit memory: Dissociable neural correlates at encoding. Journal of Cognitive Neuroscience, 14(4), 578592.

Sergent, C., Baillet, S., \& Dehaene, S. (2005). Timing of the brain events underlying access to consciousness during the attentional blink. Nature Neuroscience, 8(10), 1391.

Shang, M., \& Debruille, J. B. (2013). N400 processes inhibit inappropriately activated representations: Adding a piece of evidence from a high-repetition design. Neuropsychologia, 51(10), 1989-1997.

Sitnikova, T., Kuperberg, G., \& Holcomb, P. J. (2003). Semantic integration in videos of real-world events: An electrophysiological investigation. Psychophysiology, 40(1), 160-164. 
Spanlang, B., Nierula, B., Haffar, M., \& Debruille, J. B. (2018). Mimicking Schizophrenia: Reducing P300b by Minimally Fragmenting Healthy Participants' Selves Using Immersive Virtual Reality Embodiment. Frontiers in Human Neuroscience, 12.

Spielberger, C. D., Gorsuch, R. L., \& Lushene, R. E. (1970). Manual for the state-trait anxiety inventory.

Strauss, G. P., Allen, D. N., Jorgensen, M. L., \& Cramer, S. L. (2005). Test-retest reliability of standard and emotional stroop tasks: an investigation of color-word and picture-word versions. Assessment, 12(3), 330-337.

Tucker, M., \& Ellis, R. (1998). On the relations between seen objects and components of potential actions. Journal of Experimental Psychology: Human Perception and Performance, 24(3), 830.

Vogel, E. K., Luck, S. J., \& Shapiro, K. L. (1998). Electrophysiological evidence for a postperceptual locus of suppression during the attentional blink. Joumal of Experimental Psychology: Human Perception and Performance, 24(6), 1656.

West, W. C., \& Holcomb, P. J. (2002). Event-related potentials during discourse-level semantic integration of complex pictures. Cognitive Brain Research, 13(3), 363-375.

Westley, A., Kohút, Z., \& Rueschemeyer, S. A. (2017). “I know something you don’t know”: Discourse and social context effects on the N400 in adolescents. Journal of Experimental Child Psychology, 164, 45-54.

Zhang, D., He, W., Wang, T., Luo, W., Zhu, X., Gu, R., ... \& Luo, Y. J. (2014). Three stages of emotional word processing: an ERP study with rapid serial visual presentation. Social Cognitive and Affective Neuroscience, $9(12), 1897-1903$. 


\section{Acknowledgements}

This study was supported by the grant 194517-03 from the Natural Sciences and Engineering Research Council of Canada, allocated to the corresponding author. The funders had no role in study design, data collection and analysis, decision to publish, or preparation of the manuscript.

The data and the codes used in the study will be made confidentially available to the reviewers asking for them, and, once the paper will be accepted, to everyone.

\section{Competing financial interest statement}

The authors declare that they have no competing financial interest.

\section{Materials and correspondence}

Raw (=EEG) data of all subjects in the EEGLAB format (a MATLAB plugin), ERPs of each condition of each subject in the ERPLAB format, Excel tables of mean-voltage measures in each time-window for each subject and each condition and SPSS output files of the mixed-model ANOVAs will be available on request to the last author (only after publication). This author will respond to readers' enquiries and requests for any materials. 
From Page 20 : Table 3 Experiment 1. Friends vs. Strangers. Results of the ANOVAs run with the mean voltages of ERPs in the N1, N300,

N400 and LPP time windows (ns : not significant and - : hemiscalp not applicable for sagittal SoE)

\section{CLICK HERE TO GO BACK TO TEXT IN PAGE 20}

\begin{tabular}{|c|c|c|c|c|c|c|c|c|c|c|c|c|c|c|c|}
\hline \multirow{2}{*}{$\begin{array}{c}\text { Mean } \\
\text { voltages } \\
\text { within } \\
\text { time } \\
\text { window }\end{array}$} & \multirow{2}{*}{$\begin{array}{c}\text { Set of } \\
\text { Electrodes } \\
\quad(\text { SoE) }\end{array}$} & \multicolumn{4}{|c|}{$\begin{array}{l}\text { Main effect of social contexts } \\
\text { (groups) }\end{array}$} & \multicolumn{5}{|c|}{$\begin{array}{l}\text { Interactions of social contexts } \\
\text { with electrodes }\end{array}$} & \multicolumn{5}{|c|}{$\begin{array}{l}\text { Interaction of social contexts } \\
\text { with electrodes and hemiscalp }\end{array}$} \\
\hline & & df & $\mathbf{F}$ & $\boldsymbol{P}$ & $\mathbf{\eta}_{\mathrm{p}}^{2}$ & df & $\mathbf{F}$ & $\boldsymbol{P}$ & $\mathbf{\eta}_{\mathrm{p}}^{2}$ & $\mathbf{e}$ & df & F & $\boldsymbol{P}$ & $\mathbf{\eta}_{\mathrm{p}}^{2}$ & $\mathbf{e}$ \\
\hline \multirow{3}{*}{$\begin{array}{c}\mathrm{N} 1 \\
(110-160 \\
\mathrm{ms})\end{array}$} & Sagittal & 1,63 & 0.73 & ns & ns & 3,189 & 0.12 & ns & ns & 0.42 & - & - & - & - & - \\
\hline & Parasagittal & 1,63 & 0.73 & ns & ns & 5,315 & 0.19 & ns & $\mathrm{ns}$ & 0.22 & 5,315 & 1.10 & $\mathrm{~ns}$ & $\mathrm{~ns}$ & 0.31 \\
\hline & Lateral & 1,63 & 1.35 & ns & ns & 4,252 & 0.06 & ns & ns & 0.28 & 4,252 & 0.59 & $\mathrm{~ns}$ & ns & 0.31 \\
\hline \multirow{3}{*}{$\begin{array}{c}\text { N300 } \\
(200-350 \\
\text { ms })\end{array}$} & Sagittal & 1,63 & 13.74 & $44 \times 10^{-5}$ & 0.18 & 3,189 & 1.5 & ns & ns & 0.46 & - & - & - & - & - \\
\hline & Parasagittal & 1,63 & 12.3 & 0.001 & 0.16 & 5,315 & 5.6 & 0.013 & 0.08 & 0.26 & 5,315 & 0.32 & $\mathrm{~ns}$ & $\mathrm{~ns}$ & 0.34 \\
\hline & Lateral & 1,63 & 12.45 & 0.001 & 0.16 & 4,252 & 0.58 & ns & ns & 0.28 & 4,252 & 3.38 & 0.056 & 0.05 & 0.34 \\
\hline \multirow{3}{*}{$\begin{array}{c}\mathrm{N} 400 \\
(350-550 \\
\mathrm{ms})\end{array}$} & Sagittal & 1,63 & 20.34 & $29 \times 10^{-6}$ & 0.24 & 3,189 & 0.9 & ns & ns & 0.43 & - & - & - & - & - \\
\hline & Parasagittal & 1,63 & 20.9 & $23 \times 10^{-6}$ & 0.24 & 5,315 & 3.94 & 0.033 & 0.06 & 0.27 & 5,315 & 0.89 & ns & ns & 0.34 \\
\hline & Lateral & 1,63 & 15.61 & $19 \times 10^{-5}$ & 0.19 & 4,252 & 0.15 & ns & ns & 0.28 & 4,252 & 3.38 & $\mathrm{~ns}$ & $\mathrm{~ns}$ & 0.34 \\
\hline \multirow{3}{*}{$\begin{array}{c}\text { LPP } \\
(650-950 \\
\mathrm{ms})\end{array}$} & Sagittal & 1,63 & 8.34 & 0.005 & 0.12 & 3,189 & 0.34 & ns & ns & 0.45 & - & - & - & - & - \\
\hline & Parasagittal & 1,63 & 6.46 & 0.014 & 0.09 & 5,315 & 3.04 & ns & ns & 0.28 & 5,315 & 1.16 & $\mathrm{~ns}$ & ns & 0.42 \\
\hline & Lateral & 1,63 & 3 & ns & ns & 4,252 & 0.21 & ns & ns & 0.3 & 4,252 & 2.84 & ns & ns & 0.36 \\
\hline
\end{tabular}


From Page 21 : Table 5. Experiment 1. Results of the ANOVAs run adding the time windows as a within-group factor (ns : not significant and - : hemiscalp not applicable for sagittal SoE)

\section{CLICK HERE TO GO BACK TO TEXT IN PAGE 21}

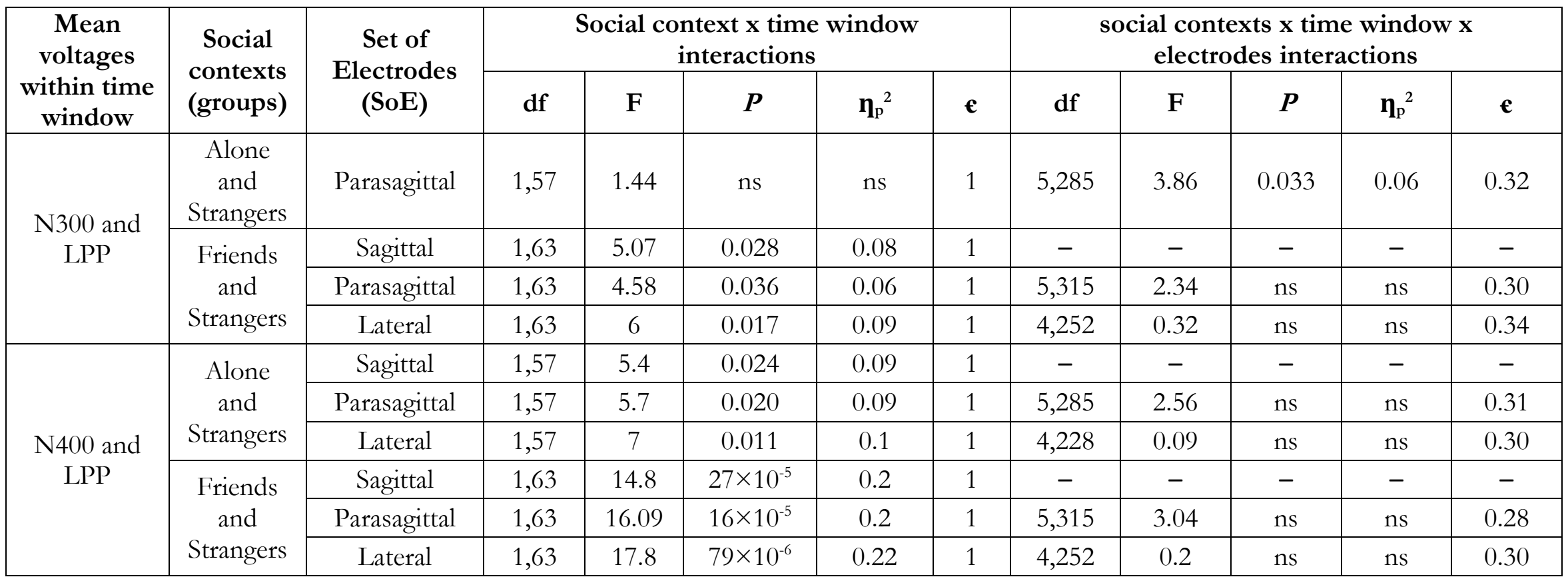




\section{APPENDIX 1}

1. Experiment 1. Channel recomputations. No channel was ignored.

\begin{tabular}{|c|c|c|c|}
\hline \multirow{2}{*}{ Group } & $\begin{array}{c}\text { Participant's } \\
\text { number }\end{array}$ & $\begin{array}{c}\text { Channels } \\
\text { recomputed }\end{array}$ & $\begin{array}{c}\text { Recomputation } \\
\text { Formulae }\end{array}$ \\
\hline \multirow{2}{*}{30 Alone } & 1 to 29. & none & $\mathrm{n} / \mathrm{a}$ \\
\cline { 2 - 4 } & 30 & $\mathrm{~F} 8$ & $\mathrm{~F} 8=\mathrm{Ft} 8$ \\
\hline 36 Friends & 1 to 36. & none & $\mathrm{n} / \mathrm{a}$ \\
\hline \multirow{3}{*}{29} & $\begin{array}{c}1,2,4,6,7,9,11,12,14,16 \\
, 18,21,23,25,26,28 .\end{array}$ & none & $\mathrm{n} / \mathrm{a}$ \\
\cline { 2 - 4 } Strangers & 3 & $\mathrm{Fc} 4$ & $\mathrm{Fc} 4=(\mathrm{F} 4+\mathrm{C} 4) / 2$ \\
\cline { 2 - 4 } & $5,8,10,13,15,17,19$, & $\mathrm{Cz}$ & $\mathrm{Fc} 4=(\mathrm{F} 4+\mathrm{C} 4) / 2$ \\
\hline
\end{tabular}




\section{APPENDIX 2 \\ Verbatim of "Felt Alone" or "Felt Together" questions asked during the debriefing session}

"We asked you to try to feel in the presence of your partner during the experiment even when the curtains were closed. Please select the option that best represents when you felt IN THE

PRESENCE OF YOUR PARTNER during the IMAGE portion of the experiment. Be sure to read the choices carefully and select the one that best applies."

o I felt in the presence of my partner during the entire image presentation.

o I felt in the presence of my partner for MORE than 50\% of the image presentation.

o I felt in the presence of my partner for about $50 \%$ of the image presentation.

o I felt in the presence of my partner for LESS than $50 \%$ of the image presentation

o I didn't feel in the presence of my partner at all during the image presentation. 
APPENDIX 3

Experiment 2. Channel recomputations and ignored channels Felt Alone (FA) subgroup $(n=47)$

\begin{tabular}{|c|c|c|c|}
\hline $\begin{array}{c}\text { Participant's } \\
\text { number }\end{array}$ & $\begin{array}{l}\text { Channel (s) } \\
\text { recomputed }\end{array}$ & Formulae & $\begin{array}{c}\text { Channels } \\
\text { ignored }\end{array}$ \\
\hline $\begin{array}{c}5,6,9 \text { to } 13, \\
15, \\
17 \text { to } 33,35 \\
\text { to } \\
44,46\end{array}$ & none & - & none \\
\hline \multirow{2}{*}{1} & Fc3 & $\mathrm{Fc} 3=(.5 *(\mathrm{Ft} 7)+\mathrm{F} 3+.5 *(\mathrm{Fcz})+\mathrm{C} 3)) / 3$ & \multirow{2}{*}{ none } \\
\hline & T3 & $\mathrm{T} 3=(\mathrm{Ft} 7+\mathrm{Tp} 7) / 2$ & \\
\hline 2 & none & $\mathrm{n} / \mathrm{a}$ & $\mathrm{O} 2$ \\
\hline \multirow{2}{*}{3} & Fc3 & $\left.\mathrm{Fc} 3=\left(.5 *(\mathrm{Ft} 7)+\mathrm{F} 3+.5^{*}(\mathrm{Fcz})+\mathrm{C} 3\right)\right) / 3$ & \multirow{2}{*}{$\mathrm{T} 5, \mathrm{Tp} 7$} \\
\hline & Fc4 & $\mathrm{Fc} 4=\left(.5^{*}(\mathrm{Fcz})+.5^{*}(\mathrm{Ft} 8)+\mathrm{F} 4+\mathrm{C} 4\right) / 3$ & \\
\hline 4 & Fc3 & $\left.\mathrm{Fc} 3=\left(.5^{*}(\mathrm{Ft} 7)+\mathrm{F} 3+.5^{*}(\mathrm{Fcz})+\mathrm{C} 3\right)\right) / 3$ & none \\
\hline 7 & Fc3 & $\left.\mathrm{Fc} 3=\left(.5^{*}(\mathrm{Ft} 7)+\mathrm{F} 3+.5^{*}(\mathrm{Fcz})+\mathrm{C} 3\right)\right) / 3$ & none \\
\hline 8 & Fc3 & $\left.\mathrm{Fc} 3=\left(.5 *(\mathrm{Ft} 7)+\mathrm{F} 3+.5^{*}(\mathrm{Fcz})+\mathrm{C} 3\right)\right) / 3$ & $\mathrm{O} 2$ \\
\hline 14 & Ft8 & $\mathrm{Ft} 8=(\mathrm{F} 8+\mathrm{T} 4) / 2$ & none \\
\hline 16 & F4 & $\mathrm{F} 4=\left(\mathrm{Fc} 4+.5^{*}(\mathrm{Fz})+.5 *(\mathrm{~F} 8)\right) / 2$ & none \\
\hline 34 & none & - & T5 \\
\hline \multirow{3}{*}{45} & $\mathrm{Tp} 7$ & $\mathrm{Tp} 7=(\mathrm{T} 3+\mathrm{T} 5) / 2$ & \multirow{3}{*}{ none } \\
\hline & $\mathrm{F} 4$ & $\mathrm{~F} 4=\left(\mathrm{Fc} 4+.5^{*}(\mathrm{Fz})+.5^{*}(\mathrm{~F} 8)\right) / 2$ & \\
\hline & F3 & $\mathrm{F} 3=\left(\mathrm{Fc} 3+.5^{*}(\mathrm{~F} 7)+.5^{*}(\mathrm{Fz})\right) / 2$ & \\
\hline 47 & none & - & T6 \\
\hline
\end{tabular}


Experiment2. Felt Together subgroup $(n=39)$. No channel was ignored.

\begin{tabular}{|c|c|c|}
\hline Participant no & $\begin{array}{l}\text { Channel(s) } \\
\text { recomputed }\end{array}$ & Formulae \\
\hline $\begin{array}{c}2,5-8,10-12 \\
14,16,18,19,21,22,24 \\
-28,33,34,36-39 .\end{array}$ & none & $\mathrm{n} / \mathrm{a}$ \\
\hline 3 & Fc3 & $\left.\mathrm{Fc} 3=\left(.5^{*}(\mathrm{Ft} 7)+\mathrm{F} 3+.5^{*}(\mathrm{Fcz})+\mathrm{C} 3\right)\right) / 3$ \\
\hline 4 & Fc3 & $\left.\mathrm{Fc} 3=\left(.5^{*}(\mathrm{Ft} 7)+\mathrm{F} 3+.5^{*}(\mathrm{Fcz})+\mathrm{C} 3\right)\right) / 3$ \\
\hline 9 & F4 & $\mathrm{F} 4=(\mathrm{Fc} 4+.5 *(\mathrm{Fz})+.5 *(\mathrm{~F} 8)) / 2$ \\
\hline 13 & P3 & $\mathrm{P} 3=(\mathrm{Cp} 3+.5 *(\mathrm{~T} 5)+.5 *(\mathrm{Pz})) / 2$ \\
\hline \multirow{2}{*}{15} & Fc4 & $\mathrm{Fc} 4=\left(.5^{*}(\mathrm{Fcz})+.5^{*}(\mathrm{Ft} 8)+\mathrm{F} 4+\mathrm{C} 4\right) / 3$ \\
\hline & F4 & $\mathrm{F} 4=(\mathrm{Fc} 4+.5 *(\mathrm{Fz})+.5 *(\mathrm{~F} 8)) / 2$ \\
\hline 17 & C3 & $\mathrm{C} 3=\left(\mathrm{Fc} 3+\mathrm{Cp} 3+.5^{*}(\mathrm{~T} 3)+.5^{*}(\mathrm{Cz})\right) / 3$ \\
\hline \multirow{2}{*}{20} & Fc4 & $\mathrm{Fc} 4=\left(.5 *(\mathrm{Fcz})+.5^{*}(\mathrm{Ft} 8)+\mathrm{F} 4+\mathrm{C} 4\right) / 3$ \\
\hline & $\mathrm{C} 4$ & $\mathrm{C} 4=\left(\mathrm{Fc} 4+\mathrm{Cp} 4+.5^{*}(\mathrm{Cz})+.5^{*}(\mathrm{~T} 4)\right) / 3$ \\
\hline 23 & - & - \\
\hline 29 & - & - \\
\hline \multirow{2}{*}{30} & $\mathrm{Tp} 7$ & $\mathrm{Tp} 7=(\mathrm{T} 3+\mathrm{T} 5) / 2$ \\
\hline & Tp8 & $\mathrm{Tp} 8=(\mathrm{T} 4+\mathrm{T} 6) / 2$ \\
\hline \multirow{2}{*}{31} & Ft7 & $\mathrm{Ft} 7=(\mathrm{F} 7+\mathrm{T} 3) / 2$ \\
\hline & F4 & $\mathrm{F} 4=\left(\mathrm{Fc} 4+.5^{*}(\mathrm{Fz})+.5^{*}(\mathrm{~F} 8)\right) / 2$ \\
\hline 32 & Cp4 & $\mathrm{Cp} 4=(\mathrm{C} 4+\mathrm{P} 4) / 2$ \\
\hline \multirow{2}{*}{35} & F7 & $\mathrm{F} 7=\mathrm{F} 8$ \\
\hline & $\mathrm{Cz}$ & $\mathrm{C}_{\mathrm{z}}=(2 \mathrm{Fcz}+\mathrm{Pz}) /$ \\
\hline
\end{tabular}




\section{*Credit Author statement}

S. S. was involved in all aspects of the first submission and of the revised version of the manuscript. S. B. run the testing of the close-other pairs of the first experiment as well as that of the stranger pairs. A. T. run the testing of the second experiment and processed its data. T. D. and N.F. run the testing of the participants who were alone. H.P., A. C-M and M. H. reprocessed S. B. data. U. H. and M. K. were involved in their interpretation. J. B. D. designed the study, supervised all authors except U. H. and M. K., wrote the first versions of the manuscript and corrected the late versions as well as the revised version written by S. S 